\title{
Análisis de facies en depósitos de grano fino asociados a flujos de fango. Formación Vaca Muerta (Tithoniano-Valanginiano), Cuenca Neuquina central, Argentina
}

\author{
*Germán Otharán ${ }^{1,2,3}$, Carlos Zavala2,3, Mariano Arcuri',3, Mariano Di Meglio 2,3, \\ Agustín Zorzano, ${ }^{2,}$, Denis Marchal ${ }^{4}$, Guillermina Köhler ${ }^{4}$
}

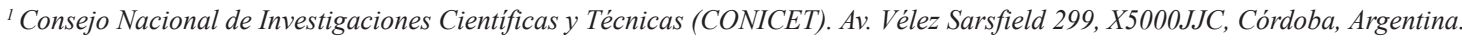 \\ german.otharan@uns.edu.ar \\ ${ }^{2}$ Geología de Cuencas Sedimentarias (GCS) Argentina S.R.L. Interna 1320, Bahía Blanca, 8000, Buenos Aires, Argentina. \\ czavala@gcsargentina.com; marcuri@gcsargentina.com; mdimeglio@gcsargentina.com; zorzan@gcsargentina.com \\ ${ }^{3}$ Departamento de Geología, Universidad Nacional del Sur, Av. Alem 1253, cuerpo B-2 ${ }^{\circ}$ Piso, Bahía Blanca, 8000, Argentina. \\ ${ }^{4}$ Pampa Energía S.A. Maipú 1, Piso 14, CABA, C1084ABA, Buenos Aires, Argentina. \\ denis.marchal@pampaenergia.com; guillermina.kohler@pampaenergia.com
}

*Autor de correspondencia: german.otharan@uns.edu.ar

RESUMEN. El modelo sedimentológico convencional relaciona la acumulación de rocas sedimentarias de grano fino $(<62,5 \mu \mathrm{m})$, ricas en materia orgánica, únicamente con procesos de decantación hemipelágica en ambientes de baja energía. En esta contribución se analizan una serie de depósitos fangolíticos con elevado contenido de materia orgánica (fangolitas bituminosas), reconocidos en los afloramientos de la sección inferior de la Formación Vaca Muerta, en áreas centrales de la Cuenca Neuquina (localidades de Arroyo Mulichinco, Tres Chorros y Río Neuquén). Este intervalo basal de la Formación Vaca Muerta es el que mayor contenido de materia orgánica presenta (hasta 8\% COT). Los depósitos fangolíticos que lo constituyen están altamente compactados, lo que produce una pérdida de resolución importante que limita el reconocimiento y el análisis de los procesos sedimentarios involucrados. Sin embargo, es común encontrar niveles milimétricos a centimétricos parcialmente cementados en concreciones carbonáticas, los cuales proveen un registro excepcional de las estructuras sedimentarias y la fábrica original presente en estos depósitos fangolíticos. Estudios de cortes macroscópicos pulidos y secciones delgadas de estos niveles cementados permitieron reconocer una serie de facies sedimentarias genéticamente asociadas a flujos de fango. Su origen se relaciona con flujos hiperpícnicos fangosos de larga duración (flujos casi estacionarios) desencadenados a partir de descargas directas de ríos en crecida durante períodos húmedos de precipitaciones extremas. En su trayectoria cuenca adentro, los flujos hiperpícnicos cargados de fango detrítico habrían atravesado zonas de muy baja pendiente e incorporado el material intracuencal disponible (lo que incluye materia orgánica) a su carga sedimentaria extracuencal. La rápida transferencia de fango rico en materia orgánica habría permitido alcanzar un soterramiento instantáneo, evitando de esta manera su potencial degradación en el fondo marino. Los flujos de fango parecen constituir un mecanismo eficiente para explicar la presencia de fangolitas bituminosas en áreas centrales de la Cuenca Neuquina.

Palabras clave: Flujos de fango, Preservación de la materia orgánica, Fangolitas bituminosas, Formación Vaca Muerta.

ABSTRACT. Facies analysis of fine-grained deposits related to muddy underflows. Vaca Muerta Formation (Tithonian-Valanginian), central Neuquen Basin, Argentina. The conventional sedimentological model suggests that the accumulation of organic-rich fine-grained sedimentary rocks $(<62.5 \mu \mathrm{m})$ is uniquely associated with fallout processes in low energy depositional environments. This contribution analyzes organic-rich mudstones belonging to the lower section of the Vaca Muerta Formation at central areas of the Neuquén Basin (Arroyo Mulichinco, Tres Chorros and Río Neuquén localities). The studied interval is characterized by the highest organic matter content of the Vaca 
Muerta Formation (up to $8 \%$ TOC). The associated mudstone deposits are usually highly compacted, thus obscuring the recognition of the original fabric and the analysis of mudstone depositional processes. Nevertheless, the common occurrence of carbonate concretions within these highly compacted intervals provides an exceptional preservation of mudstone primary fabric. After macroscopic study of polished slabs and thin sections of these cemented beds, a series of facies genetically linked to muddy underflows were recognized. The origin of these deposits is related to long-lived muddy hyperpycnal flows (quasi-steady mud flows) triggered by extreme river discharges during rainfall humid periods. During their travel basinward, hyperpycnal flows, originally composed of detrital mud, would be able to go through very low gradient reliefs, incorporating the available intrabasinal components (including organic matter) to their extrabasinal sedimentary load. The rapid basinward transfer of organic-rich mud would have provided a fast deposition and efficient burial of organic matter, avoiding its potential degradation at seafloor. Muddy underflows constitute a rational mechanism to explain the common occurrence of bituminous mudstones at central areas of the Neuquén Basin.

Keywords: Mud flows, Organic matter preservation, Bituminous mudstones, Vaca Muerta Formation.

\section{Introducción}

Históricamente, la acumulación de materiales finos $(<62,5 \mu \mathrm{m})$ con abundante contenido orgánico ha sido relacionada únicamente con procesos de decantación hemipelágica en ambientes marinos de costa afuera dominados por aguas calmas y fondos anóxicos (Tyson et al., 1979; Demaison y Moore, 1980; Schlanger et al., 1987; O’Brien y Slatt, 1990; Bhattacharya y Walker, 1992; Boggs, 2001). Sin embargo, estos ambientes suelen presentar una productividad orgánica relativamente baja y por lo general no reciben aportes significativos de materia orgánica. A su vez, el largo camino que debe atravesar dicha materia a través de la extensa columna de agua es un factor importante que contribuye a su potencial degradación (Arthur et al., 1984; Stow et al., 2001).

Por otro lado, considerando los grandes espesores y el grado de compactación que presentan las rocas sedimentarias de grano fino, se necesitarían tasas de sedimentación absurdas o bien tiempos muy prolongados para acumular espesores semejantes de fango a partir de plumas de decantación. Hacia fines del siglo XX, estas incógnitas e incertidumbres acerca del modelo de decantación promovieron el desarrollo de estudios sedimentológicos de alta resolución en secuencias litológicas de grano fino, los cuales documentaron por primera vez la presencia de depósitos y estructuras sedimentarias que no concordaban con el modelo depositacional preexistente (Stow y Shanmugam, 1980; Seilacher y Einsele, 1982; Stow y Piper, 1984; Macquaker y Gawthorpe, 1993; Macquaker, 1994; Schieber, 1994, 1998). Sin embargo, los procesos sedimentarios involucrados fueron pobremente comprendidos hasta hace pocos años, cuando comenzaron a realizarse ensayos de laboratorio en canales artificiales que resultaron transcendentales para entender la dinámica del transporte y acumulación de materiales finos (Schieber et al., 2007, 2013; Schieber y Southard, 2009; Schieber y Yawar, 2009; Baas et al., 2009, 2011; Schieber, 2011). Los resultados de estos estudios desencadenaron un paulatino cambio de paradigma en la sedimentología de los depósitos de grano fino, lo que permitió una completa reevaluación de los modelos de acumulación antiguamente propuestos (Soyinka y Slatt, 2008; Bhattacharya y MacEachern, 2009; Schieber et al., 2010; Abouelresh y Slatt, 2011; Plint et al., 2012; Könitzer et al., 2014; Bohacs et al., 2014; Wilson y Schieber, 2014, 2015; Schieber, 2016; Zavala y Arcuri, 2016). Al mismo tiempo, el avance de técnicas no convencionales de explotación de hidrocarburos puso interés adicional en obtener una mejor comprensión de los procesos sedimentarios que controlan la acumulación de materiales finos con abundante contenido de materia orgánica, a modo de predecir aquellos intervalos con mayor potencial hidrocarburífero. En Argentina el principal foco de estudio es la Formación Vaca Muerta (Tithoniano temprano-Valanginiano temprano), dado el potencial que presentan las rocas de esta unidad como reservorio no convencional de hidrocarburos (Askenazi et al., 2013; Stinco y Barredo, 2014). En este contexto, se han desarrollado numerosos trabajos interdisciplinarios tanto desde el ámbito académico (Leanza et al., 2011; Kietzmann et al., 2011, 2014a, b, c, 2015, 2016; entre otros) como privado (Askenazi et al., 2013; Galeazzi et al., 2014; González et al., 2016, entre otros). Estas contribuciones han realizado valiosos aportes al análisis sedimentológico, estratigráfico, secuencial y paleoambiental del intervalo Tithoniano temprano-Valanginiano temprano de la Cuenca Neuquina (formaciones Vaca Muerta y Quintuco). 
En este estudio se da a conocer una serie de depósitos fangolíticos ricos en materia orgánica (fangolitas bituminosas) reconocidos en la sección inferior de la Formación Vaca Muerta, ubicados en áreas centrales de la Cuenca Neuquina (localidades de Arroyo Mulichinco, Tres Chorros y Río Neuquén), cuyo origen parece estar asociado a flujos de fango (Otharán y Zavala, 2016, 2018; Otharán et al., 2017; Otharán et al., 2018a, b). Estos depósitos están altamente compactados y, asimismo, suelen sufrir una importante meteorización, lo cual dificulta su reconocimiento en los afloramientos. A pesar de lo anterior, existen concreciones carbonáticas originadas durante la diagénesis temprana que preservan la fábrica primaria de los depósitos fangolíticos, lo cual permite abordar estudios sedimentológicos de alta resolución en los depósitos asociados. El objetivo de este trabajo es discutir el origen de estos depósitos fangolíticos y asimismo el rol de los flujos de fango en la transferencia de materia orgánica desde las zonas de mayor producción hasta áreas depocentrales ubicadas en sectores internos de la Cuenca Neuquina.

\section{Marco Geológico}

La Cuenca Neuquina se encuentra localizada en el centro-oeste de Argentina, entre los paralelos 34 y $40^{\circ} \mathrm{S}$ (Fig. 1). Presenta una forma triangular que abarca una superficie de aproximadamente $160.000 \mathrm{~km}^{2}$ (Vergani et al., 1995), limita al noreste con el Sistema de la Sierra Pintada y al sureste con el Macizo Norpatagónico, mientras que su extremo occidental lo define el arco magmático andino. Constituye una cuenca de retroarco multiepisódica desarrollada sobre corteza continental (Mpodozis y Ramos, 1989), cuyo origen habría estado vinculado a la evolución del margen occidental de Gondwana durante el Paleozoico tardío-Mesozoico (Mosquera et al., 2011).

La historia depositacional de la Cuenca Neuquina estuvo íntimamente relacionada con la evolución del arco volcánico activo ubicado al oeste, el cual habría controlado la conexión con el océano Pacífico y ocasionado una serie de inundaciones-desecaciones que se manifiestan repetidamente en el registro sedimentario de la cuenca (Legarreta y Uliana, 1991; Mutti et al., 1994). Sus depósitos representan una sucesión predominantemente clástica de hasta $7.000 \mathrm{~m}$ de sedimentitas marinas y continentales acumuladas en su mayoría durante el Jurásico y el Cretácico. Estos depósitos fueron agrupados en tres grandes ciclos sedimentarios separados por discordancias de carácter regional: "Jurásico", "Ándico" y "Riográndico" (Groeber, 1946). El primero de estos ciclos abarca los grupos Precuyo, Cuyo y Lotena, mientras que el segundo comprende los grupos Mendoza y Rayoso. Finalmente, el ciclo Riográndico reúne a los grupos Neuquén y Malargüe (Fig. 1).

\subsection{La Formación Vaca Muerta}

La Formación Vaca Muerta (Weaver, 1931, enmend. Leanza, 1973) constituye una unidad espesa de sedimentitas marinas acumuladas durante el Jurásico tardío-Cretácico temprano en la Cuenca Neuquina (Fig. 1). En el ámbito de la provincia de Neuquén, esta unidad se compone principalmente por una sucesión heterogénea de fangolitas arcillosas bituminosas intercaladas con fangolitas calcáreas y silíceas, entre las cuales es común encontrar niveles de calizas intercalados (Kietzmann et al., 2014a, b, 2016). Estos depósitos presentan un elevado contenido de materia orgánica (3-8\% carbono orgánico total; Legarreta y Villar, 2015), lo cual convierte a la Formación Vaca Muerta en la roca madre de hidrocarburos más importante de Argentina. Asimismo, esta unidad tiene excelentes propiedades como reservorio no convencional de hidrocarburos, hecho que ha despertado gran interés en la industria durante los últimos años, y la ha convertido actualmente en el principal reservorio shale de Sudamérica (Askenazi et al., 2013; Stinco y Barredo, 2014; González et al., 2016).

\subsubsection{Posición estratigráfica}

La Formación Vaca Muerta pertenece al Grupo Mendoza (Stipanicic et al., 1968) y forma parte de la Mesosecuencia Mendoza Inferior de Legarreta y Gulisano (1989), que abarca la totalidad de los depósitos comprendidos entre la discordancia Intramálmica y la Intravalanginiana. Este ciclo sedimentario se inicia con depósitos clásticos continentales correspondientes a la Formación Tordillo y equivalentes (Kimmeridgiano), la cual es sucedida en forma neta-transgresiva por depósitos marinos

${ }^{1}$ Otharán, G.A.; Zavala, C. 2018. Muddy hyperpycnal flows and organic-rich shales. In Workshop on Deep Water Sedimentation, No. 1: 10-11. Bahía Blanca. 


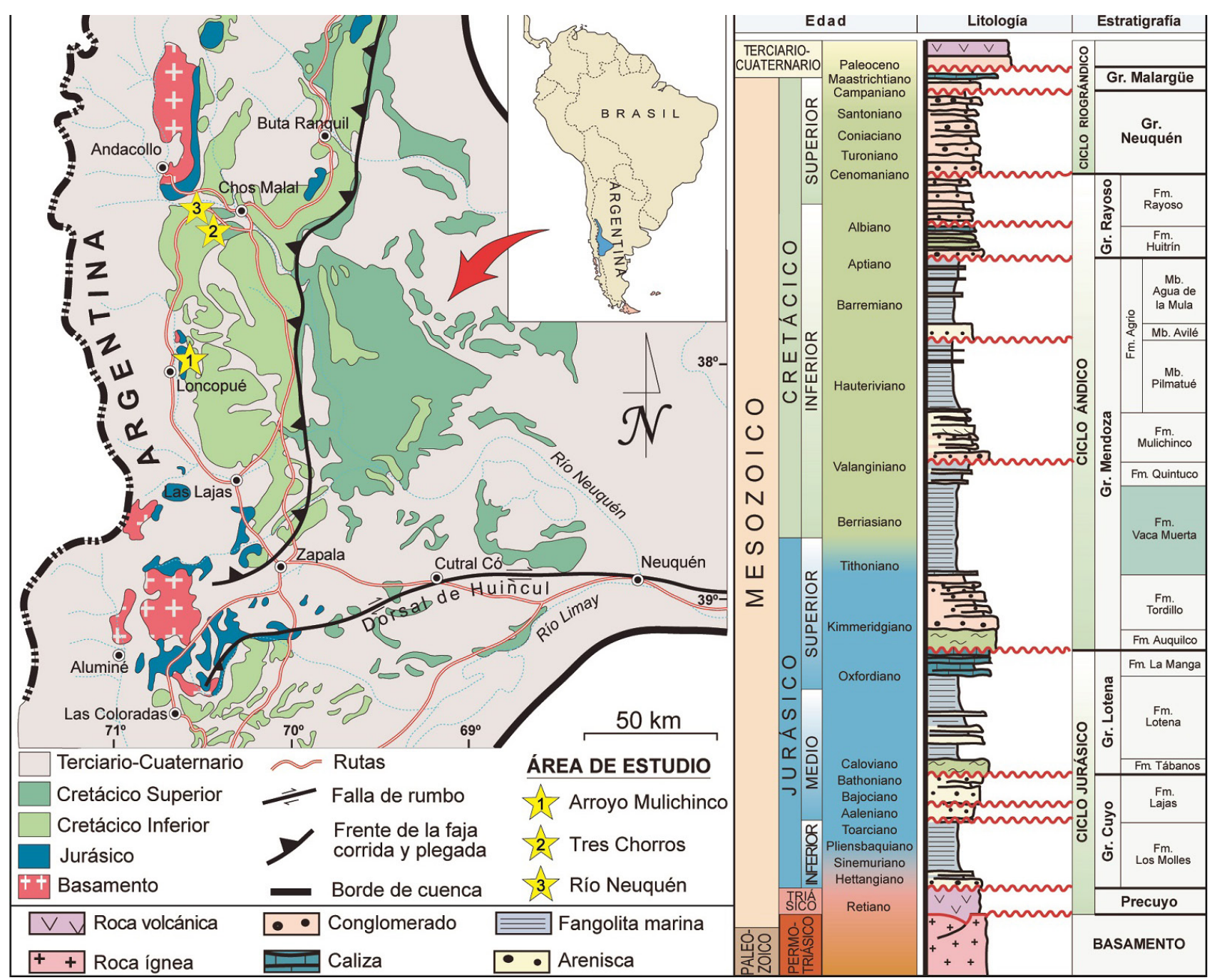

FIG. 1. Mapa geológico y columna estratigráfica esquemática de la región central de la Cuenca Neuquina (Modificado de Zavala et al., 2006). 
de offshore de la Formación Vaca Muerta (Fig. 1). Su origen se asocia a un aumento abrupto del nivel del mar acontecido en el Tithoniano temprano, suceso que habría generado una rápida y catastrófica ingresión marina que cubrió prácticamente toda la cuenca y excedió ampliamente los límites paleogeográficos previos (Mutti et al., 1994).

Este importante evento transgresivo favoreció el desarrollo de una sección condensada basal con un patrón de apilamiento retrogradante, definida por Mitchum y Uliana (1985) como Secuencia A. Estos depósitos muestran un contenido de materia orgánica de hasta $12 \%$ COT, por lo que constituyen la principal fuente de hidrocarburos de la Cuenca Neuquina (Legarreta y Villar, 2015; González et al., 2016). Hacia el techo, la Formación Vaca Muerta está cubierta en contacto transicional y diacrónico por las rocas de la Formación Quintuco y equivalentes (Weaver, 1931), las que representan un sistema de plataforma mixta progradante hacia el oeste-noroeste (e.g., Mitchum y Uliana, 1985).

Mitchum y Uliana (1985) reconocieron un total de nueve secuencias depositacionales (A-I) para el sistema Vaca Muerta-Quintuco; en ella la Secuencia A representa la base de la Formación Vaca Muerta (Tithoniano temprano) y la Secuencia I el techo de la Formación Quintuco (Valanginiano temprano). El trabajo de Mitchum y Uliana (1985) fue recientemente complementado con la elaboración de una sección sísmica regional de más de $300 \mathrm{~km}$ de extensión, en donde se recopiló una gran cantidad de información de subsuelo (sísmica, registros de pozos, testigos corona), y se incorporaron, asimismo, datos de afloramiento (González et al., 2016). En esta contribución, las secuencias depositacionales reconocidas por Mitchum y Uliana (1985) para el sistema Vaca Muerta-Quintuco (A-I) fueron divididas en seis unidades sísmicas (U1-U6) separadas por horizontes de distribución regional (Sattler et al., 2016; Desjardins et al., 2016).

El sistema Vaca Muerta-Quintuco comienza con una configuración inicial de rampa mixta desarrollada durante el Tithoniano temprano-medio (secuencias A-C, Mitchum y Uliana, 1985; unidades 1-2, Sattler et al., 2016), la cual presenta un arreglo predominantemente agradacional compuesto por clinoformas de muy bajo ángulo (Desjardins et al., 2016). Hacia el Tithoniano tardío, la configuración inicial de rampa habría evolucionado a un sistema de plataforma mixta con quiebre de pendiente extendido hasta el Valanginiano temprano (Gulisano et al., 1984; Mitchum y Uliana, 1985; Legarreta y Gulisano, 1989; Leanza et al., 2011). La instalación de un sistema de plataforma habría sido posible gracias a un importante aporte clástico proveniente del Macizo Norpatagónico durante un período de mar alto (Leanza et al., 2011), lo cual resultó en el desarrollo de un complejo sistema de clinoformas sigmoidales y oblicuas progradantes hacia el O-NO (secuencias D-I, Mitchum y Uliana, 1985; unidades 3-6, Sattler et al., 2016).

Por su parte, los depósitos típicos de la Formación Vaca Muerta se encuentran asociados a los segmentos de foresets y bottomsets de las clinoformas, que represecntan las facies distales del sistema depositacional (González et al., 2016). Su mayor desarrollo ocurre en áreas depocentrales ubicadas en el margen occidental de la cuenca, con espesores que llegan a superar los $1.150 \mathrm{~m}$ (Leanza, 1973). Se destaca la presencia de un intervalo turbidítico emplazado en la sección media/superior de la Formación Vaca Muerta en el área de Huncal, definido por Leanza et al. (2003) como Miembro Huncal, y asignado al Berriasiano temprano.

Por otro lado, las facies proximales del sistema se encuentran mayoritariamente desarrolladas en el ámbito del Engolfamiento Neuquino, en donde se reconocen segmentos de topsets integrados por depósitos marino-marginales de las formaciones Quintuco y Loma Montosa (Tithoniano tardíoValanginiano temprano), y culminan con depósitos continentales asignados a la Formación Puesto González (Valanginiano temprano, Mitchum y Uliana, 1985). En el sector austral de la Cuenca Neuquina, estos depósitos marinos someros son referidos a las formaciones Carrín Curá y Picún Leufú, mientras que los depósitos continentales se agrupan en la Formación Bajada Colorada (Leanza et al., 2011).

\section{3. Área de estudio y metodología}

El área de estudio se encuentra ubicada en el centro-oeste de la provincia de Neuquén, en uno de los depocentros más importantes de la Cuenca Neuquina, donde la Formación Vaca Muerta alcanza su máximo desarrollo. Se han seleccionado dos localidades principales (Arroyo Mulichinco y Tres Chorros) y una localidad complementaria adicional (Río Neuquén):

Arroyo Mulichinco. Se levantó una columna estratigráfica de las formaciones Vaca Muerta y 
Quintuco, desde el contacto basal de la Formación Vaca Muerta con la Formación Tordillo sobre el valle del arroyo Mulichinco, hasta el límite entre las formaciones Quintuco y Mulichinco, ubicado próximo a la cumbre del cerro homónimo. En esta columna, paralelamente con la descripción sedimentológica, se efectuó un muestreo sistemático de las rocas de la Formación Vaca Muerta para estudios de geoquímica orgánica (\% COT). A su vez, en la sección inferior de esta unidad sobre el margen norte del arroyo Mulichinco, se tomaron 14 muestras (AM-01/AM-14) de depósitos fangolíticos de espesor centimétrico-milimétrico preservados en el interior de concreciones carbonáticas de hasta $1 \mathrm{~m}$ de diámetro, las cuales fueron destinadas a la realización de cortes macroscópicos pulidos y secciones delgadas para posteriores estudios sedimentológicos (Fig. 2A).

Tres Chorros. Se levantó una columna estratigráfica de las formaciones Vaca Muerta y Quintuco, desde el contacto de la primera con la Formación Tordillo, reconocida sobre el valle del arroyo El Huecú hasta la discordancia Intravalanginiana que define la base de la Formación Mulichinco. Paralelamente con la descripción sedimentológica, se tomaron 8 muestras de concreciones carbonáticas presentes en la sección inferior del perfil, con el objetivo de analizar los procesos de sedimentación asociados a flujos de fango (TC-01/TC-08).

Río Neuquén. En esta sección complementaria se analizaron depósitos fangolíticos excepcionalmente preservados en el interior de concreciones carbonáticas presentes en la sección basal de la Formación Vaca Muerta. Asimismo, se tomaron 9 muestras de concreciones carbonáticas para posteriores estudios sedimentológicos (RN-01/RN-09).

\subsection{Columnas estratigráficas}

Las secciones estratigráficas fueron medidas con báculo de Jacob, capa a capa, de base a techo, y se describieron detalladamente todos aquellos rasgos sedimentológicos reconocibles en las unidades de roca. El registro de los datos se efectuó en forma digital mediante el uso del programa LithoHero, diseñado específicamente para levantamiento de columnas estratigráficas (Iparraguirre et al., 2016, 2018²). El relevamiento estratigráfico de las columnas fue complementado con medidas de rayos gamma $(\mathrm{RG})$ con una densidad de 3 medidas/báculo mediante el empleo de un scintilómetro portátil (Exploranium GR-113) a fin de posibilitar la construcción de un registro de RG.

\subsection{Análisis de carbono orgánico total (COT \%)}

Se efectuaron determinaciones de carbono orgánico total (COT) en muestras de roca de la Formación Vaca Muerta correspondientes al perfil de Arroyo Mulichinco, para obtener un registro continuo del contenido orgánico de esta unidad en sectores internos de la Cuenca Neuquina. El estudio se realizó sistemáticamente en muestras recolectadas a lo largo de todo el perfil, con una densidad de muestreo de 1 muestra cada 1,5 $\mathrm{m}$ de espesor estratigráfico en los primeros $100 \mathrm{~m}$ de espesor acumulado; luego la densidad de muestreo se redujo a 1 muestra cada $3 \mathrm{~m}$ de espesor estratigráfico. El estudio se hizo por combustión seca sobre un total de 295 muestras, con un Analizador Automático de Carbono LECO (CR-12).

\subsection{Cortes pulidos de concreciones carbonáticas}

La ejecución de cortes macroscópicos pulidos de rocas constituye una técnica sencilla y útil para el análisis sedimentológico de sucesiones litológicas de grano fino (Schieber, 1994, 1998). Sin embargo, no existen menciones en la bibliografía acerca de estudios sedimentológicos en secciones pulidas de concreciones carbonáticas. Estos cuerpos cementados suelen presentar una compactación muy baja, dado que su crecimiento ocurre durante la diagénesis temprana, próximo a la interfaz agua-sedimento (Westphal et al., 2000; Lash y Blood, 2004; Abouelresh y Slatt, 2012). Como resultado de ello se genera una estructura rígida capaz de soportar la carga litostática a medida que progresa el soterramiento (Bathurst, 1970), lo que proporciona un registro excepcional de las estructuras sedimentarias primarias y de la fábrica original presente en depósitos fangolíticos (Kietzmann y Palma, 2011; Kietzmann et al., 2014a, b, c, 2016; Otharán y Zavala, 2016, 2018; Otharán et al., 2017). Si bien existen procesos diagenéticos tardíos que generan cuerpos cementados de morfología similar a las concreciones (frecuentemente referidos

\footnotetext{
${ }^{2}$ Iparraguirre, J.; Arcuri, M.; Zavala, C.; Di Meglio, M.; Zorzano, A. 2018. Lithohero: Creating comprehensive sedimentary logs from cores and outcrops. In Workshop on Deep Water Sedimentation 1: p. 6. Bahía Blanca.
} 
como nódulos), es importante resaltar que estos cuerpos se encuentran constituidos principalmente por concentraciones de minerales autigénicos que durante su crecimiento producen una deformación de los sedimentos adyacentes (Sellés-Martínez, 1996). Por tales razones, estos cuerpos no resultan de interés a este trabajo.

La técnica empleada consiste en muestrear concreciones carbonáticas que a priori exhiban los rasgos sedimentarios primarios (Fig. 2B y C).
Luego, las muestras son sometidas al proceso de corte y pulido para finalmente ser escaneadas y procesadas digitalmente para alcanzar una mejor caracterización (Fig. 2D). Se realizaron 31 cortes macroscópicos pulidos de concreciones carbonáticas distribuidas en la sección inferior de la Formación Vaca Muerta (Figs. 3 y 4). Se observó que en algunos casos la fábrica primaria puede encontrarse obliterada por procesos diagenéticos (recristalización y/o reemplazo), lo cual dificulta el reconocimiento de
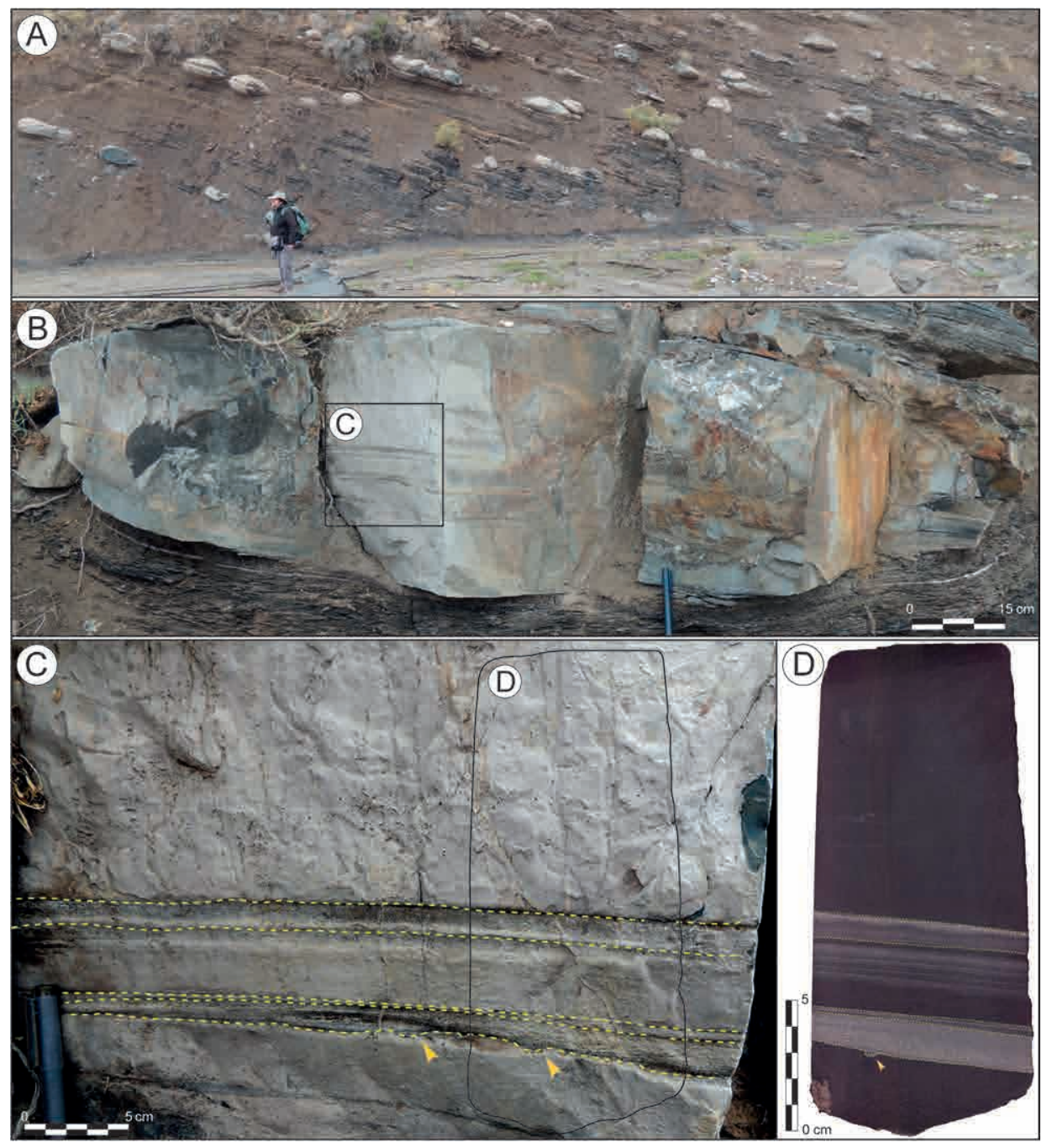

FIG. 2. Concreciones carbonáticas en la Formación Vaca Muerta. A. Concreciones alineadas según el plano de estratificación en la sección inferior de la Formación Vaca Muerta en el perfil de Arroyo Mulichinco (Fig. 3B). B-C. Preservación excepcional de la fábrica primaria en el interior de una concreción. Se reconocen marcas de erosión asociadas a procesos de erosión (flechas amarillas). D. Corte pulido de la concreción exhibida en C. Nótese la resolución milimétrica que permiten obtener los intervalos cementados, lo cual facilita el análisis de procesos de sedimentación en sucesiones finas $(<62,5 \mu \mathrm{m})$. 
los rasgos sedimentarios primarios de los depósitos fangolíticos asociados.

\subsection{Análisis de facies}

Se realizó un análisis descriptivo de facies a escala milimétrica-centimétrica en depósitos fangolíticos contenidos en el interior de concreciones carbonáticas. Es necesario aclarar que el análisis de facies fue empleado con la finalidad de lograr un mejor entendimiento de los procesos sedimentarios asociados al transporte y depositación de materiales finos $(<62,5 \mu \mathrm{m})$.

Para la descripción y caracterización de los depósitos finos se utilizó la clasificación de Lazar et al. (2015a). Luego, sobre la base de las características macroscópicas-mesoscópicas primarias reconocidas en los cortes pulidos de concreciones carbonáticas, se definieron diferentes litofacies genéticamente vinculadas. Posteriormente las facies fueron calibradas con estudios petrográficos de secciones delgadas, orientados a la caracterización textural de cada facies; se analizó, asimismo, el arreglo interno de sus componentes primarios y, en menor medida, se hicieron alusiones en cuanto a su composición.

Para la clasificación de las facies se utilizó una nomenclatura puramente descriptiva, la cual permite, a priori, conocer las principales características que definen a cada litofacies. Esta nomenclatura comprende un código de tres letras similar al propuesto por Miall (1985), donde las dos primeras hacen referencia a la composición textural, indicándose con mayúscula el tipo de litología y en minúscula, como subíndice, el tamaño de grano predominante. La letra restante se coloca en mayúscula y señala la estructura sedimentaria predominante en cada facies. Así, por ejemplo, la facies FgM corresponde a fangolitas gruesas (Fg) macizas (M), mientras que la facies FsR hace referencia a fangolitas arenosas (Fs) con laminación ondulítica de corriente (R). Esta nomenclatura tiene la ventaja de ser flexible, ya que permite la incorporación de nuevas facies al esquema inicial.

\section{Resultados}

Los resultados se presentan en dos columnas que resumen la estratigrafía de la Formación Vaca Muerta en el área de estudio (Figs. 3 y 4). Junto con dichas columnas se presentan los estudios de COT y las mediciones de rayos gamma.

\subsection{Columnas estratigráficas}

\subsubsection{Arroyo Mulichinco}

En esta sección la Formación Vaca Muerta se dispone en contacto neto sobre areniscas y heterolitas verdosas de la Formación Tordillo, y es cubierta en forma transicional por la Formación Quintuco, la cual tiene muy poca expresión en esta localidad y es rápidamente sucedida por bancos conglomerádicos correspondientes a la Formación Mulichinco, cuya base define la discordancia Intravalanginiana (Fig. 3A). En esta localidad, la Formación Vaca Muerta alcanza un espesor de aproximadamente $1.370 \mathrm{~m}$ y está compuesta principalmente por fangolitas finas a medias bituminosas, con intercalaciones de fangolitas calcáreas y bancos menores de calizas (mudstone/wackestone). Para su descripción, esta columna ha sido dividida en tres intervalos:

Sección inferior (0-585 m). La base de la Formación Vaca Muerta está definida por delgados bancos de calizas mudstone con amonites, y continúa con fangolitas finas a medias bituminosas intercaladas con niveles de fangolitas finas a gruesas calcáreas con restos de valvas y amonites (Fig. 3A y B). Estos depósitos también se caracterizan por la presencia de restos vegetales y pirita, y en forma subordinada aparecen niveles de calizas (mudstone/wackestone) de hasta $45 \mathrm{~cm}$ de espesor. Es común la presencia de vetillas de calcita fibrosa (beef) de hasta $10 \mathrm{~cm}$ de espesor. Asimismo, la sección inferior de la Formación Vaca Muerta contiene intercalaciones de delgados niveles tobáceos y concreciones carbonáticas alineadas según el plano de estratificación (Figs. 2A y 3B). Estas últimas pueden alcanzar un desarrollo de hasta $1 \mathrm{~m}$ de diámetro, e internamente se caracterizan por presentar estructuras sedimentarias primarias tales como laminación ondulítica, laminación paralela y gradación interna, además de estructuras de erosión asociadas a niveles de pirita oxidada (Fig. 2C y D). Los depósitos contenidos en el interior de las concreciones carbonáticas serán tratados en detalle más adelante a partir del análisis sedimentológico de diferentes cortes macroscópicos pulidos (5. Análisis de facies).

Sección media (585-1.045 m). En este intervalo disminuye considerablemente el contenido de carbonato presente en las sucesiones finas. Del mismo modo, los niveles de concreciones carbonáticas se encuentran disminuidos, al igual que las vetillas de calcita fibrosa (tipo beef). 


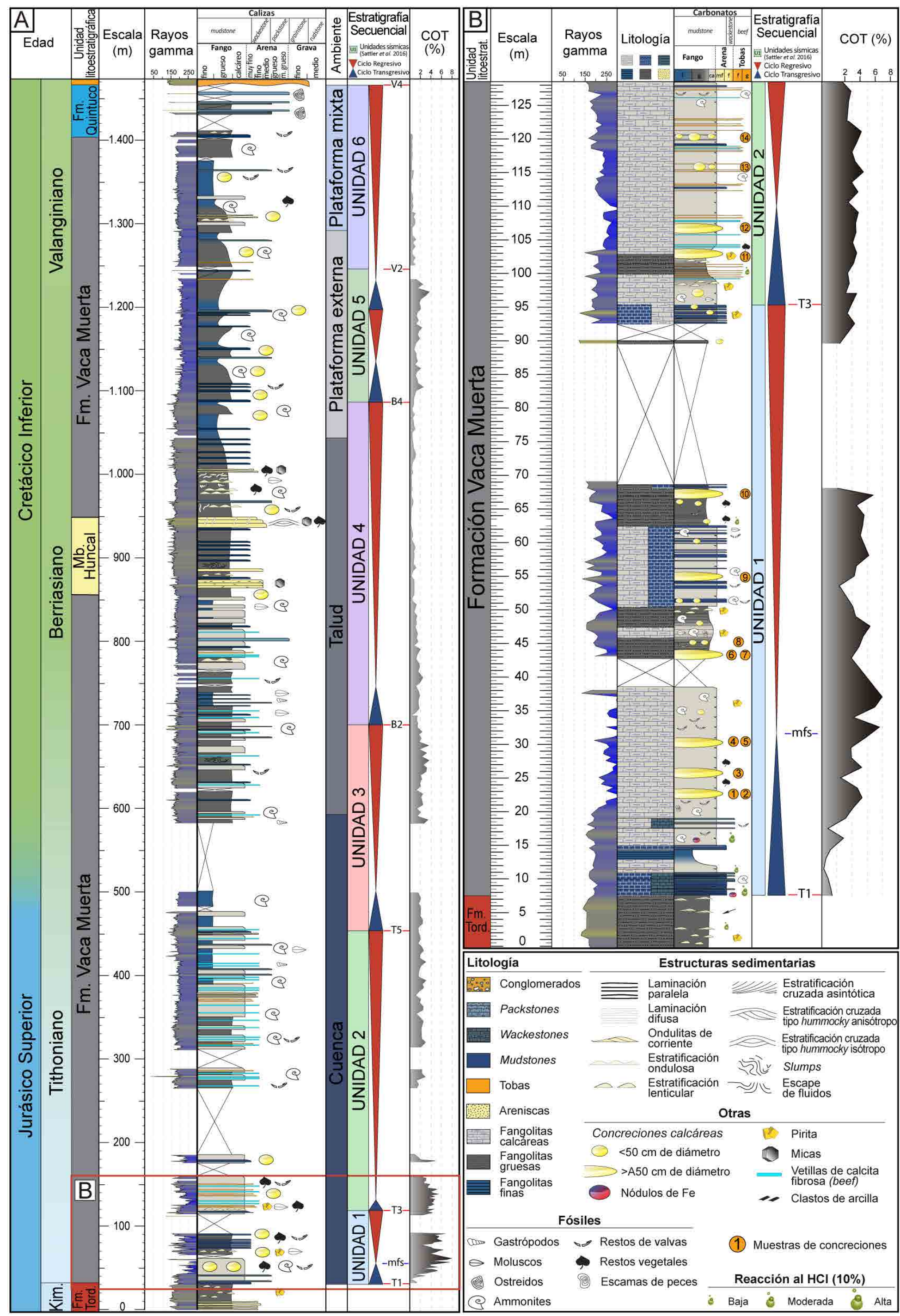

FIG. 3. A. Columna estratigráfica de la Formación Vaca Muerta en el perfil de Arroyo Mulichinco. Se presenta un registro de rayos gamma y una curva de carbono orgánico total (\% COT) obtenida a partir del análisis de 295 muestras. Se correlacionan las diferentes secuencias compuestas reconocidas (ciclos transgresivo-regresivos) con las unidades sísmicas definidas por Sattler et al. (2016) y Desjardins et al. (2016). B. Detalle del intervalo condensado basal de la Formación Vaca Muerta. Estos depósitos son los que mayor cantidad de materia orgánica presentan, con picos de hasta $8 \%$ COT. Se realizó un muestreo específico de niveles de concreciones carbonáticas para el análisis de los procesos de sedimentación asociados (muestras AM-01/AM-14). 


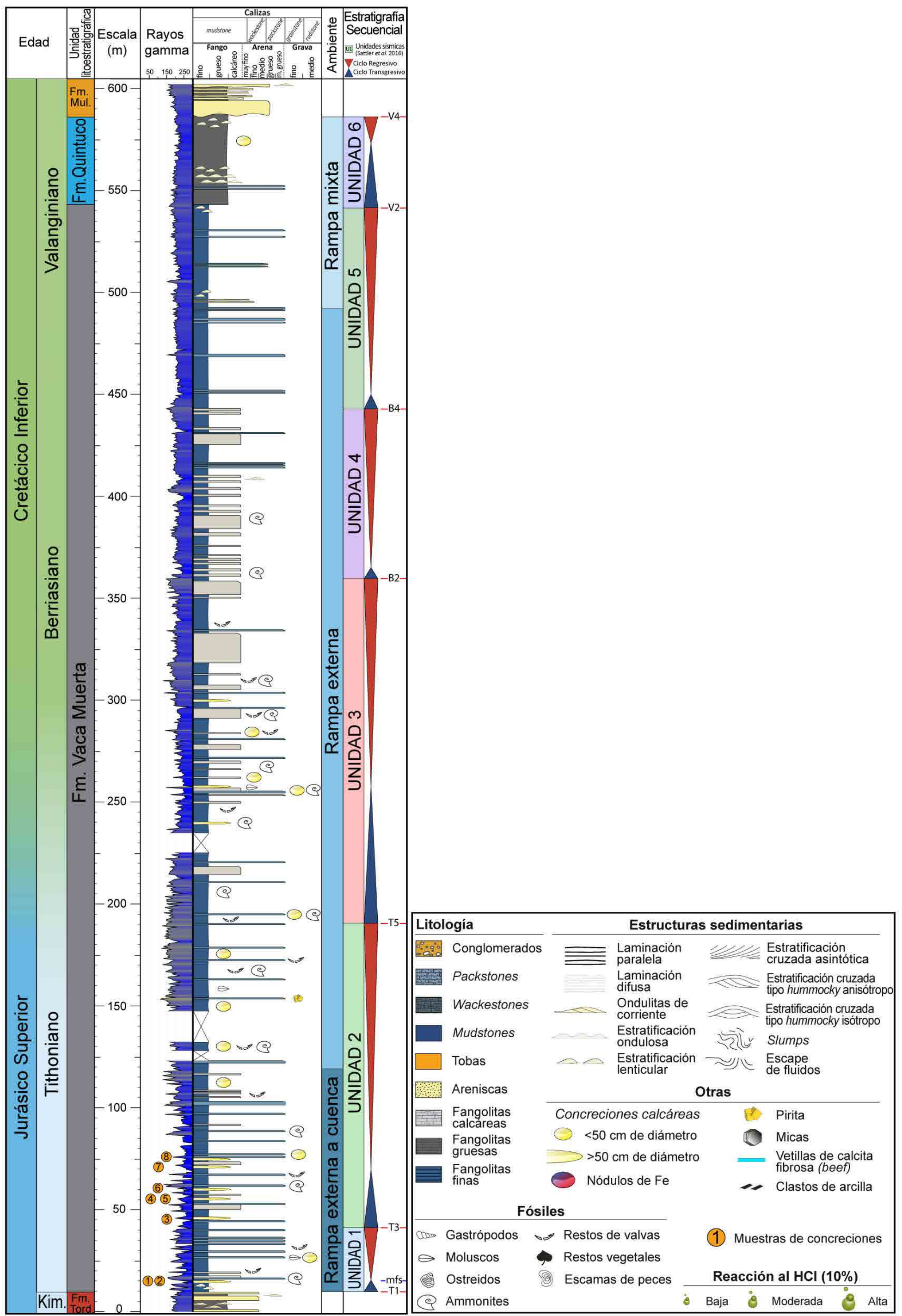

FIG. 4. Columna estratigráfica de la Formación Vaca Muerta en el perfil de Tres Chorros. Se presenta un registro de rayos gamma. Las secuencias compuestas reconocidas (ciclos transgresivoregresivos) fueron correlacionadas con las unidades sísmicas definidas por Sattler et al. (2016). Se tomaron muestras de concreciones carbonáticas presentes en la sección inferior de la Formación Vaca Muerta con la finalidad de estudiar los procesos de sedimentación asociados (muestras TC-01/TC-08). 
En esta sección se han reconocido deslizamientos sinsedimentarios (slumps) en depósitos de fangolitas calcáreas y calizas mudstone (Fig. 3A). Hacia el tope de este intervalo aparece una sucesión clástica arenosa de aproximadamente $80 \mathrm{~m}$ de espesor, la cual correspondería a los depósitos que Leanza et al. (2003) definieron como Miembro Huncal. Este miembro está representado por bancos de areniscas finas a medias macizas, a veces con estratificación cruzada tipo hummocky isótropo (HCSi), ondulas de corriente y marcas de erosión asociadas, entre los que se intercalan niveles de fangolitas medias con estratificación lenticular y ondulosa. Los depósitos que componen el Miembro Huncal muestran una composición mixta (silicoclástica-carbonática) y están caracterizados por una interdigitación de componentes intracuencales (carbonatos, intraclastos arcillosos, amonites) y extracuencales (clastos detríticos, restos vegetales, micas). Hacia el techo, los bancos de areniscas del Miembro Huncal se encuentran parcialmente bioturbados. Este intervalo culmina con fangolitas finas a medias con estratificación lenticular y ondulosa, entre las que se intercalan delgados niveles de calizas (mudstone). Es común la presencia de restos vegetales y micas asociados a las facies heterolíticas, las que en algunos sectores se encuentran levemente bioturbadas (Fig. 3A).

Sección superior (1.045-1.481 m). Este intervalo cuspidal de la Formación Vaca Muerta se caracteriza por fangolitas finas a gruesas intercaladas con delgados bancos de calizas (mudstone). En cuanto al contenido de niveles cementados, se reconoce un escaso desarrollo de concreciones carbonáticas, las cuales rara vez se encuentran alineadas. A su vez, los niveles de vetillas de calcita fibrosa están muy poco representados. Hacia el tope, en un intervalo semicubierto ubicado justo por debajo de la base de la Formación Mulichinco, aparecen niveles de calizas (packstone y rudstone) de hasta $0,8 \mathrm{~m}$ de espesor. Este acotado intervalo cuspidal predominantemente carbonático se atribuye a la Formación Quintuco, unidad que tendría una representación muy escasa en el área de estudio. La base de la Formación Mulichinco está definida por la súbita aparición de conglomerados clasto-soportados con estratificación cruzada asintótica y estratificación cruzada tipo hummocky anisótropo (HCSa).

Interpretación. Los depósitos correspondientes a la sección inferior de la Formación Vaca Muerta en la localidad de Arroyo Mulichinco se corresponden con un ambiente de cuenca dominado por fondos anaeróbicos (Spalletti et al., 2008), hecho que habría favorecido la preservación de la materia orgánica. En este contexto paleoambiental, la depositación de los materiales finos que integran este intervalo habría ocurrido principalmente a partir dos mecanismos principales: flujos de fango y procesos de decantación hemipelágica (Otharán et al., 2018a). Asimismo, los depósitos volcaniclásticos presentes se habrían acumulado a partir de procesos de decantación desde nubes de ceniza, que quedaron sujetos a un posterior retrabajo por medio de flujos de fango (Otharán et al., 2018a). Por otro lado, los niveles de calizas (mudstone/wackestone) que intercalan con las facies finas se habrían acumulado a partir de corrientes de fondo desencadenadas durante eventos de tormenta, tal como lo describen Kietzmann et al. (2014b, 2016) en el área de Puerta Curaco.

A partir del análisis del perfil de rayos gamma, se interpreta que la sección inferior de la Formación Vaca Muerta abarca tanto las unidades 1 y 2 como el intervalo inferior de la Unidad 3 de Sattler et al. (2016). Estas unidades representan grandes ciclos transgresivo-regresivos o secuencias compuestas (Kietzmann et al., 2014a), y sus límites están generalmente asociados a niveles carbonáticos (Fig. 3A). El pasaje entre cortejos transgresivos y regresivos dentro de cada secuencia se relaciona con intervalos de fangolitas bituminosas con elevado COT y con niveles de concreciones carbonáticas asociados (Fig. 3B).

Particularmente, la Unidad 1 representa una sección condensada basal de aproximadamente $90 \mathrm{~m}$ de espesor, caracterizada por fangolitas calcáreas bituminosas con abundantes concreciones carbonáticas. Estos depósitos fangolíticos son los que mayor contenido de materia orgánica tienen, con valores medios de $4 \%$ COT y picos máximos de hasta $8 \%$ COT. Los rasgos sedimentarios primarios preservados en el interior de las concreciones (superficies de erosión, truncaciones internas en la laminación, ondulas de fango, gradación normal/inversa) permiten asociar el origen de parte de los depósitos fangolíticos contenidos dentro de la Unidad 1 a flujos de fango (Otharán et al., 2018a). Lo mismo ocurre para aquellos depósitos asociados al intervalo basal de la Unidad 2 (2,16-5,14\% COT). Los depósitos restantes (unidades 2 y 3 ) ubicados hacia el techo de la sección inferior muestran un contenido orgánico significativamente menor, con un valor promedio de $2,103 \%$ COT. 
Los depósitos que integran la sección media de la Formación Vaca Muerta muestran el pasaje desde un ambiente de cuenca a un medio de talud, reflejado por la presencia de deslizamientos gravitacionales y depósitos turbidíticos (Miembro Huncal, Leanza et al., 2003; Spalletti et al., 2008). Esta sección se corresponde con el intervalo superior de la Unidad 3 y prácticamente la totalidad de la Unidad 4 de Sattler et al. (2016), las cuales muestran geometrías de clinoformas progradantes de alto ángulo (Desjardins et al., 2016). A partir del análisis de líneas sísmicas, Pose et al. (2014) y Arregui (2014) relacionan reflectores de tipo caótico con deslizamientos gravitacionales en la Unidad 3 (Desjardins et al., 2016). De esta manera, la acumulación de los materiales que componen la sección media de la Formación Vaca Muerta en el perfil de Arroyo Mulichinco habría estado controlada por flujos gravitativos de sedimentos, desencadenados a partir de desestabilizaciones del talud, el cual, de acuerdo con Leanza et al. (2003), estaría ubicado en el margen occidental activo de la cuenca (Spalletti et al., 2008). El contenido orgánico de este intervalo es significativamente menor que en la sección inferior, con valores comprendidos entre 0,20 y $3,64 \%$ COT (Fig. 3A), en concordancia con los estudios de geoquímica orgánica presentados por González et al. (2016) para las unidades 3 y 4 del sistema Vaca Muerta-Quintuco.

Los depósitos de la sección media de la Formación Vaca Muerta podrían estar asociados a un talud depositacional desarrollado a partir de las sucesivas progradaciones provenientes del sur; estos depósitos componen las unidades 3 y 4 del sistema Vaca Muerta-Quintuco (Sattler et al., 2016). Esto fue previamente advertido por Naipauer et al. (2015), quienes a partir de edades U-Pb en circones detríticos contenidos en los niveles arenosos del Miembro Huncal, interpretan un área de aporte ubicada en los márgenes austral y oriental de la cuenca. De esta manera, el origen de los depósitos que componen la sección media de la Formación Vaca Muerta podría estar vinculado tanto a flujos intracuencales asociados a desestabilizaciones del talud como a flujos hiperpícnicos generados a partir de descargas directas provenientes de ríos en crecida (shelf-margin deltas). Por su parte, los depósitos mixtos que componen el Miembro Huncal (representados principalmente por bancos de areniscas macizas con abundantes restos vegetales) podrían relacionarse con un sistema de canales y lóbulos hiperpícnicos depositados en un medio de talud-pie de talud. Asimismo, la bioturbación comúnmente asociada a estos depósitos podría estar vinculada a la incorporación de los organismos productores en zonas proximales del sistema, transportándolos junto con la carga sedimentaria extracuencal hasta el quiebre de la plataforma, donde habría ocurrido su acumulación en sectores de alta pendiente y habrían conformado un sistema de clinoformas progradantes de alto ángulo (unidades 3 y 4).

Finalmente, la sección superior de la Formación Vaca Muerta se asociaría a un ambiente de plataforma silicoclástica externa (Unidad 5) que hacia el techo habría evolucionado a una plataforma mixta silicoclástica-carbonática, la cual representa la transición a la Formación Quintuco (Unidad 6, Sattler et al., 2016). Los depósitos finos de este intervalo se habrían acumulado a partir de procesos de decantación hemipelágica (González et al., 2016), mientras que las facies carbonáticas estarían vinculadas a eventos de tormenta de variada duración y magnitud (Kietzmann et al., 2014a, 2016). Al igual que en la sección media, los valores de COT son generalmente bajos en este intervalo cuspidal $(0,20-3,70 \%$ COT $)$.

\subsubsection{Tres Chorros}

En este perfil, la Formación Vaca Muerta se dispone en contacto neto sobre bancos de areniscas y heterolitas correspondientes a la Formación Tordillo, mientras que su techo está definido por un pasaje transicional a la Formación Quintuco, la cual está representada por un intervalo de aproximadamente $40 \mathrm{~m}$ compuesto por fangolitas arenosas con intercalaciones de calizas (packstone). Estos depósitos son cubiertos por espesos bancos de areniscas macizas correspondientes a la Formación Mulichinco, cuya base define la discordancia Intravalanginiana (Fig. 4). En claro contraste con el perfil de Arroyo Mulichinco, en esta sección la Formación Vaca Muerta alcanza un espesor de aproximadamente $530 \mathrm{~m}$.

Litológicamente, la Formación Vaca Muerta está integrada por fangolitas finas a medias grisáceas con importantes intercalaciones de calizas (wackestonel packstone). Los intervalos finos se componen de fangolitas arcillosas que alternan con bancos de 3 a $5 \mathrm{~m}$ de fangolitas calcáreas laminadas, los cuales alcanzan su mayor desarrollo en la sección media de la Formación Vaca Muerta (230-440 m). Por otro 
lado, la sección basal de esta misma formación se caracteriza por una sucesión de fangolitas finas bituminosas con frecuentes intercalaciones de calizas (packstone) y niveles de concreciones carbonáticas de hasta $50 \mathrm{~cm}$ de diámetro alineadas según el plano de estratificación (Fig. 4). A diferencia del perfil de Arroyo Mulichinco, en esta localidad los niveles tobáceos aparecen en forma subordinada. Asimismo, la presencia de fangolitas bituminosas con vetillas de calcita fibrosa (beef) es significativamente menor.

Los depósitos que integran la sección cuspidal de la Formación Vaca Muerta en el perfil de Tres Chorros (440-575 m) están compuestos por fangolitas finas a gruesas con delgados niveles heterolíticos intercalados y presencia de calizas (wackestonel packstone) de hasta $50 \mathrm{~cm}$ de espesor (Fig. 4). Hacia el techo se observa un relativo aumento en las facies heterolíticas y, además, los intervalos de fangolitas muestran un tamaño de grano grueso a arenoso (485-575 m). Estos depósitos se corresponden con las facies distales de la Formación Quintuco.

Interpretación. De forma análoga al perfil de Arroyo Mulichinco, los depósitos basales de la Formación Vaca Muerta en esta localidad se encuentran representados por una sección condensada de $20 \mathrm{~m}$ de espesor, correlacionada con la Unidad 1 de Sattler et al. (2016). A diferencia del perfil de Arroyo Mulichinco, en esta localidad se interpreta una configuración inicial de rampa restringida a cuenca, la cual abarcaría tanto la Unidad 1 como el intervalo inferior de la Unidad 2, y alcanzaría un desarrollo de $160 \mathrm{~m}$ de espesor (Fig. 4). Estos depósitos son equivalentes a la Asociación de Facies 1 de Kietzmann et al. (2014b, 2016), y son el resultado de la interacción de procesos de decantación y flujos de fango de distinta naturaleza. Los depósitos asociados a estos flujos se encuentran bien documentados en el interior de los niveles de concreciones carbonáticas presentes en esta sección (Otharán et al., 2017, 2018a), y serán tratados en detalle a continuación (5. Análisis de facies sedimentarias). Asimismo, las calizas (packstone) que aparecen intercaladas con los depósitos fangolíticos se relacionan con eventos de tormenta que habrían desencadenado corrientes de fondo (Kietzmann et al., 2014a, 2016) y habrían favorecido el transporte de importantes cantidades de material bioclástico desde ambientes de rampa media a proximal hacia porciones distales del sistema.
A diferencia del perfil de Arroyo Mulichinco, en la localidad de Tres Chorros no se observa desarrollado un sistema de plataforma, talud y cuenca, sino que se interpreta un sistema de bajo gradiente con un pasaje transicional desde un ambiente de rampa restringida cuenca a un ambiente de rampa externa. En esta localidad, los depósitos turbidíticos correspondientes al Miembro Huncal no se encuentran presentes, y tampoco se reconocieron rasgos sedimentarios asociados a procesos de resedimentación. Esto contrasta con las interpretaciones de Spalletti et al. (2008), quienes describen depósitos turbidíticos asimilables al Miembro Huncal en la sección superior de la Formación Vaca Muerta en la vecina localidad de Rahueco y los asignan al Berriasiano tardíoValanginiano temprano (Spalletti et al., 2008). Se interpreta que las areniscas referidas por Spalletti et al. (2008) al Miembro Huncal en realidad representan la secuencia basal de la Formación Mulichinco, la que en la localidad de Rahueco se inicia con lóbulos arenosos de plataforma.

La evolución del conjunto Vaca Muerta-Quintuco hacia un sistema de rampa externa está evidenciada por una mayor participación de depósitos carbonáticos, tal como lo sugieren Kietzmann et al. (2016) para la Asociación de Facies 2 presente en las localidades de Yesera del Tromen y Puerta Curaco. Esta configuración se extiende hasta los $480 \mathrm{~m}$ (Fig. 4), desde los depósitos comprendidos entre el intervalo superior de la Unidad 2 hasta la sección media de la Unidad 5 (Sattler et al., 2016). Finalmente, el sistema evolucionaría a una rampa mixta dominada por una sedimentación clástica-carbonática bajo condiciones de mayor energía, lo que representa el pasaje transicional de la Formación Vaca Muerta (intervalo superior de la Unidad 5) a la Formación Quintuco (Unidad 6).

\section{Análisis de facies sedimentarias}

El análisis sedimentológico realizado en 31 cortes pulidos de concreciones carbonáticas permitió reconocer una variedad de depósitos fangolíticos que pueden agruparse básicamente en 4 facies sedimentarias: fangolitas gruesas macizas ( $\mathrm{FgM}$ ), fangolitas arenosas con laminación ondulítica (FsR), fangolitas arenosas con laminación paralela (FsL) y fangolitas finas macizas (FfM). En la tabla 1 se describen las principales características de cada facies, se mencionan los procesos sedimentarios que le habrían dado origen y se indica en qué muestras fueron reconocidas. 
TABLA 1. DESCRIPCIÓN E INTERPRETACIÓN GENÉTICA DE FACIES SEDIMENTARIAS ASOCIADAS A FLUJOS DE FANGO, IDENTIFICADAS EN LA SECCIÓN BASAL DE LA FORMACIÓN VACA MUERTA EN LA PARTE CENTRAL DE LA CUENCA NEUQUINA (LOCALIDADES DE ARROYO MULICHINCO, RÍO NEUQUÉN Y TRES CHORROS). (*)

\begin{tabular}{|c|c|c|c|c|c|c|c|}
\hline \multicolumn{8}{|c|}{ Análisis de facies } \\
\hline \multicolumn{2}{|c|}{ Facies } & \multirow{2}{*}{\begin{tabular}{|c|} 
Base \\
\\
Neta/erosival \\
transicional
\end{tabular}} & \multirow{2}{*}{\begin{tabular}{|c|}
$\begin{array}{c}\text { Estructuras } \\
\text { sedimentarias }\end{array}$ \\
Macizo, \\
gradación \\
normal/inversa
\end{tabular}} & \multirow{2}{*}{\begin{tabular}{|c|}
$\begin{array}{c}\text { Espesor } \\
\text { (cm) }\end{array}$ \\
\\
\\
$0,3-3,5$ \\
\end{tabular}} & \multirow{2}{*}{\begin{tabular}{|c|} 
Muestra/s \\
AM: 01, 02, 03, \\
$06,07,08,09,10$, \\
12, 14; RN: 01, \\
$02,03,04,06,08$, \\
$09:$ TC: 02,05 \\
07. \\
\end{tabular}} & \multicolumn{2}{|l|}{ Origen } \\
\hline $\begin{array}{l}\text { Fangolitas } \\
\text { gruesas } \\
\text { macizas }\end{array}$ & FgM & & & & & $\begin{array}{l}\text { Transporte de fango grueso en suspensión } \\
\text { turbulenta en flujos con alta tasa de } \\
\text { decantación. Acumulación rápida de la carga } \\
\text { suspendida. }\end{array}$ & 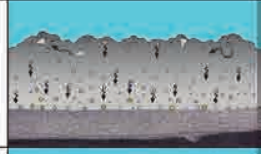 \\
\hline $\begin{array}{l}\text { Fangolitas } \\
\text { arenosas con } \\
\text { laminación } \\
\text { ondulítica }\end{array}$ & & Erosiva/neta & $\begin{array}{c}\text { Laminación } \\
\text { continua curvada } \\
\text { no paralela }\end{array}$ & $>1,5$ & $\begin{array}{c}\text { AM: 01, 04; RN: } \\
01,02,03,04,05, \\
\text { 06; TC: } 03,06 .\end{array}$ & $\begin{array}{l}\text { Flujos de fango unidireccionales diluidos. } \\
\text { Transporte de particulas por tracción, y en } \\
\text { menor medida en suspensión turbulenta. }\end{array}$ & \\
\hline $\begin{array}{c}\text { Fangolitas } \\
\text { arenosas con } \\
\text { laminación } \\
\text { paralela }\end{array}$ & 焉FsL & Neta/erosiva & $\begin{array}{c}\text { Laminación } \\
\text { planar continua } \\
\text { subparalela }\end{array}$ & $<0,7-1,8$ & $\begin{array}{l}\text { AM: 01, 06, 07, } \\
13 ; \text { RN: } 01,02 \\
03,04 ; 09 ; \text { TC: } \\
01,05,07,08\end{array}$ & $\begin{array}{c}\text { Flujos de fango sujetos a ligeras fluctuaciones } \\
\text { en la velocidad de flujo. Decantación selectiva } \\
\text { de las particulas transportadas en suspensión } \\
\text { turbulenta. }\end{array}$ & in in \\
\hline $\begin{array}{l}\text { Fangolitas } \\
\text { finas } \\
\text { macizas }\end{array}$ & Ffm & $\begin{array}{c}\text { Netal } \\
\text { transicional }\end{array}$ & $\begin{array}{l}\text { Macizo, } \\
\text { laminación } \\
\text { planar difusa } \\
\text { discontinua }\end{array}$ & $1 \rightarrow 10$ & 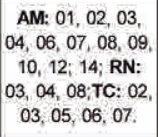 & $\begin{array}{l}\text { Decantación rápida de fango fino, materia } \\
\text { orgánica y microfósiles contenidos en flujos } \\
\text { fluidos de fango desacelerantes. }\end{array}$ & \\
\hline
\end{tabular}

(*) Se detallan las muestras donde han sido reconocidas las diferentes facies estudiadas. De un total de 31 cortes macroscópicos pulidos, en 4 muestras (AM-05, AM-11, RN-07 y TC-04) se observa una fábrica primaria completamente obliterada debido a procesos diagenéticos, razón por la cual estas muestras no fueron utilizadas en la caracterización de las diferentes facies sedimentarias.

Como puede observarse en la figura 5A y B, estos depósitos suelen presentarse en sucesivas capas gradadas de espesor variable $(<1-5 \mathrm{~cm})$, las que comúnmente se encuentran delimitadas por contactos erosivos (Fig. 5C, D y E). En algunos casos, los límites de capas están definidos por un nivel anaranjado de pirita oxidada que se reconoce muy bien en la superficie externa de las concreciones (Fig. 5F). Las capas pueden tener gradación normal o eventualmente gradación inversa (Fig. 5A y B). Las variaciones granulométricas preliminares surgidas a partir de la observación directa de los cortes macroscópicos pulidos fueron posteriormente ajustadas mediante estudios de secciones delgadas. La perfecta preservación de la fábrica primaria en estos depósitos se asocia a la ausencia de bioturbación sumada a una cementación temprana que produjo un "congelamiento" de la fábrica depositacional.

A continuación, se realizará una descripción detallada de cada facies y se harán interpretaciones acerca de su origen. Es destacable que gran parte de las facies son composicionalmente mixtas, integradas por una interdigitación de componentes detríticos extracuencales y componentes intracuencales (intraclastos, calciesferas, agregados de materia orgánica).

\subsection{Facies FgM: fangolitas gruesas macizas}

\subsubsection{Descripción}

La facies FgM está integrada por fangolitas gruesas macizas silíceas. Suele disponerse en forma transicional (Fig. 6A y B) sobre facies de fangolitas finas macizas (FfM) o eventualmente facies laminadas (FsL), o bien define bases netas/erosivas (E, Fig. 6C, D y E). Como puede observarse en el corte pulido de la muestra AM-01 (Fig. 6D), cuando la facies FgM define bases erosivas, es común encontrar marcas de erosión (Me, Fig. 6D y E) u ocasionalmente estructuras de deformación asociadas, entre las que se reconocen estructuras en llamarada (flame) y laminación convoluta.

Las estructuras deformacionales no se reconocen con facilidad, sino que su identificación solo es factible en cortes macroscópicos pulidos. La facies FgM está compuesta por fango grueso $(>32 \mu \mathrm{m})$ detrítico de color grisáceo, representado por clastos de cuarzo y 


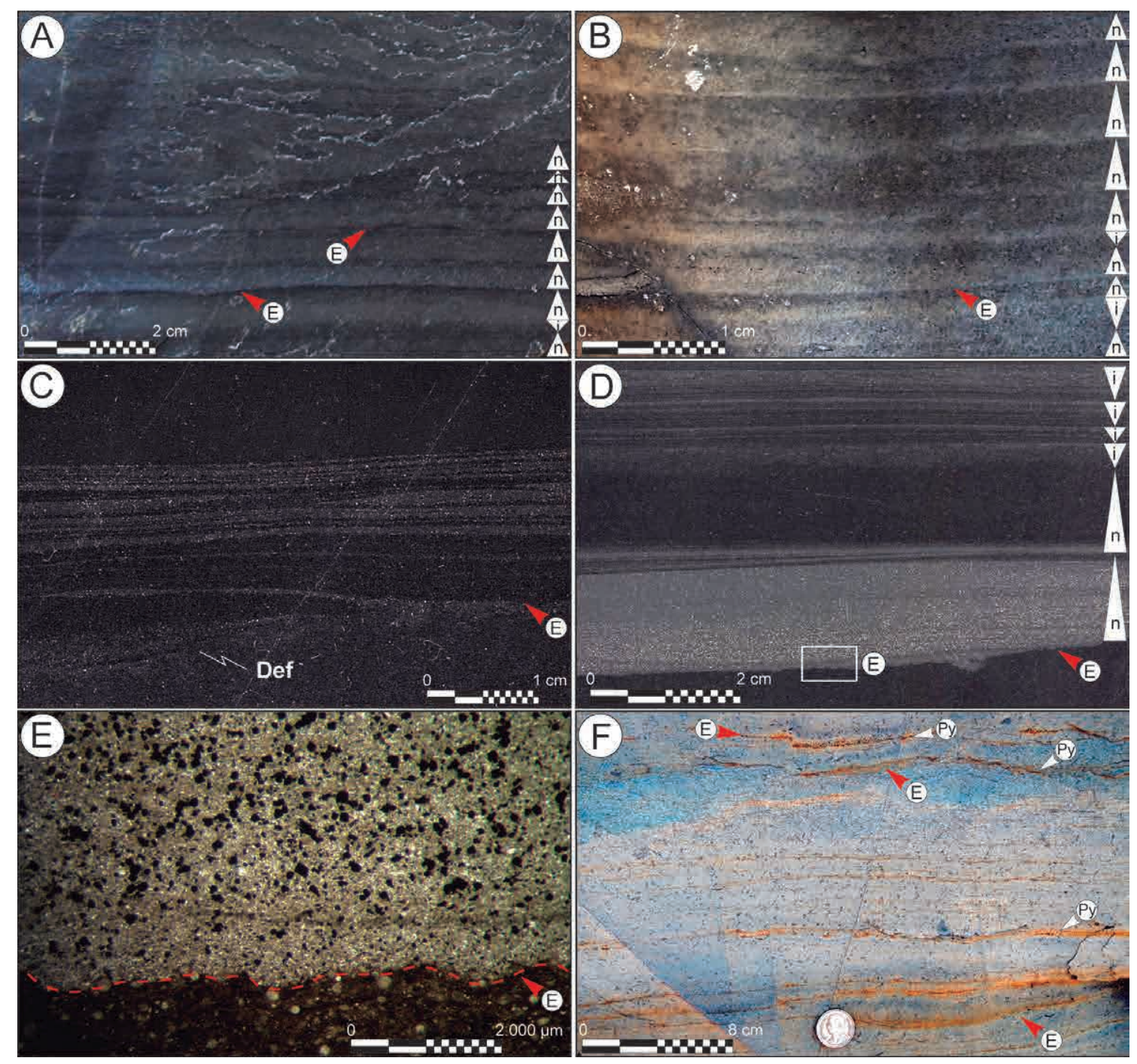

FIG. 5. A-B. Capas gradadas (ver triángulos: n-gradación normal; i-gradación inversa) de espesor milimétrico delimitadas por bases netas a erosivas (E) (muestras AM-10 y AM-12, respectivamente). C. Estructuras de deformación (Def) asociadas a bases erosivas (E) y laminación curvada continua no paralela, asociada a ondulas de fango (muestra RN-06). D. Nótese la tendencia granocreciente/granodecreciente (n-gradación normal; i-gradación inversa) de las diferentes láminas que componen esta capa, así como también la presencia de depósitos macizos y laminados (muestra AM-01). E. Detalle del contacto erosivo observado en D. Marcas de erosión asociadas a la erosión de un sustrato fangoso en estado firme. Sobre la base erosiva se disponen materiales detríticos de tamaño fango grueso. F. Aspecto de los depósitos de fango próximos a la superficie externa de concreciones carbonáticas. Se observan límites de capas netos/erosivos (E) con niveles anaranjados de pirita oxidada (Py) asociados (afloramiento sector Arroyo Mulichinco).

plagioclasa, con algunos líticos subordinados (Fig. 6E y F). Además, se caracteriza por presentar un arreglo macizo, aunque en algunos casos puede tener laminación planar difusa, discontinua, paralela (Fig. 6D).

Interpretación. La base erosiva asociada a la facies FgM se relaciona con flujos de fango que se desplazan por el fondo a una velocidad $\left(\mathrm{V}_{\text {flujo }}\right)$ suficiente para erosionar el sustrato fangoso $\left(\mathrm{V}_{\text {flujo }}>\right.$ $\mu_{\text {erosión }}$ (Umbral de erosión de sustratos fangosos), Schieber, 1998). A medida que avanza la erosión, el material removido del fondo es progresivamente incorporado a la carga sedimentaria del flujo, lo que contribuye a 

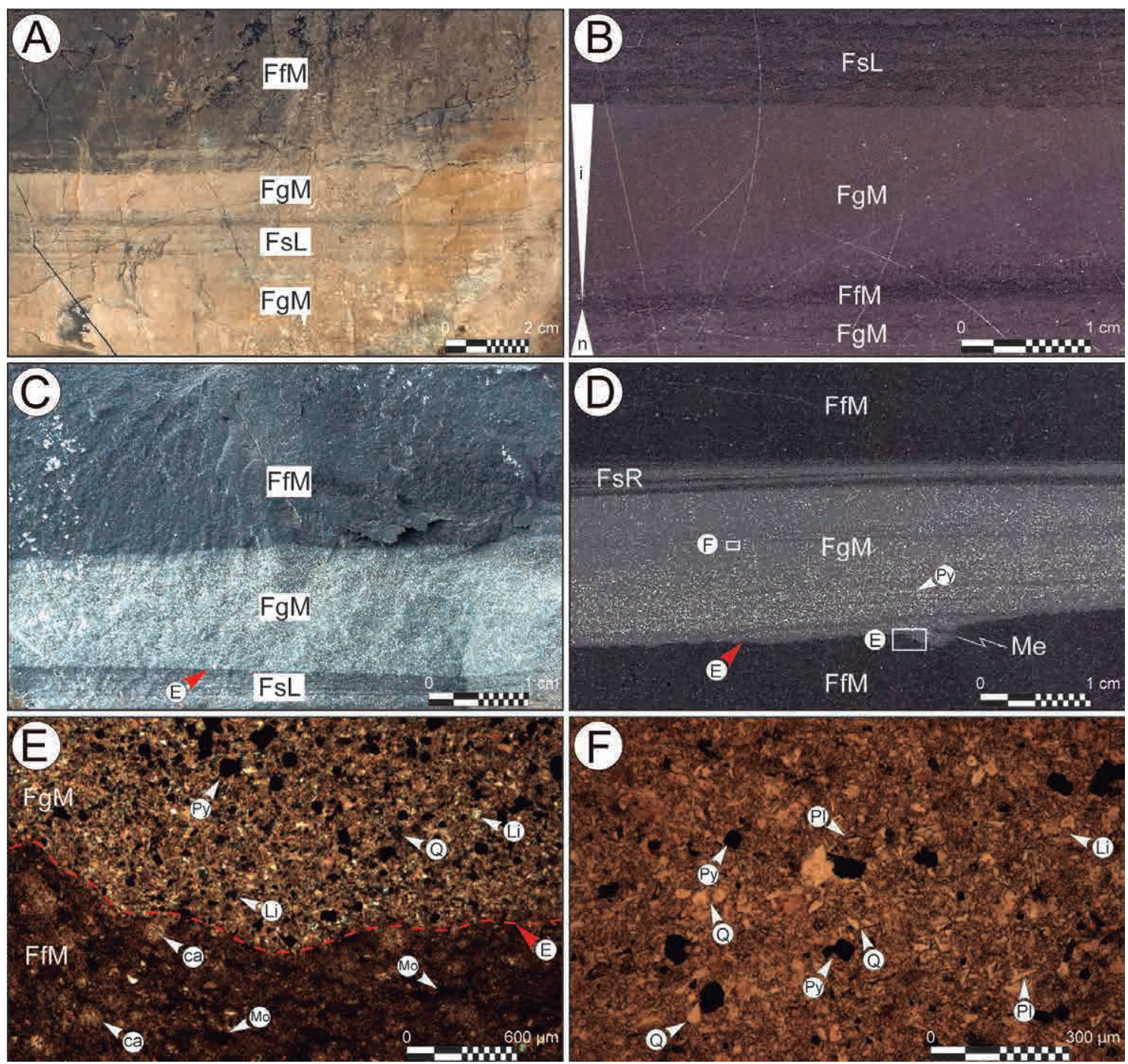

FIG. 6. Facies FgM (fangolitas gruesas macizas). A. FgM en superficie externa de concreción carbonática (afloramiento sector Río Neuquén); B. Pasaje transicional entre FgM y FfM (muestra RN-04). Nótese la tendencia granodecreciente/granocreciente presente en esta muestra (ver triángulos: n-gradación normal; i-gradación inversa); C. Contacto erosivo (E) de FgM sobre FsL (muestra TC-02); D. FgM dispuesta en base erosiva sobre FfM (muestra AM-01). Presencia de marcas de erosión asociadas (Me); E. Detalle del contacto erosivo (E) presente en D. La superficie de erosión es irregular y establece un fuerte contraste litológico entre los depósitos subyacentes y suprayacentes. Nótese la presencia de agregados de materia orgánica posiblemente amorfa en FfM (Mo) y calciesferas (ca); F. Componentes de la facies FgM, integrada principalmente por materiales detríticos tamaño fango grueso $(32-62 \mu \mathrm{m})$. Se observan clastos de cuarzo (Q), plagioclasa (Pl), fragmentos líticos (Li) y pirita (Py).

un aumento de su concentración sedimentaria. Cuando la facies FgM se dispone en base neta, se interpreta que hubo un período de no depositación entre los depósitos subyacentes y FgM (Lazar et al., 2015b). Esta pausa en la sedimentación puede estar asociada a un mismo evento depositacional, lo cual sugiere un aumento en la velocidad de flujo que inhibe la acumulación de fango, pero asimismo no alcanza a erosionar el fondo fangoso $\left(\mathrm{m}_{\text {sedimentación }}\right.$ (Velocidad crítica de acumulación de fango) $<\mathrm{V}_{\text {flujo }}<\mu_{\text {erosión }}$ ).

La etapa de erosión/no depositación es sucedida por otra agradacional en donde tiene lugar la acumulación de fango grueso transportado en suspensión turbulenta una vez que el flujo ha 
entrado en fase de desaceleración. El arreglo interno macizo sugiere una acumulación rápida a partir de flujos con importante concentración de fango en suspensión turbulenta (Baas et al., 2011). De esta manera, la rápida acumulación de la carga sedimentaria habría inhibido el desarrollo de facies laminadas (FsR, FsL).

\subsection{Facies FsR: fangolitas arenosas con laminación ondulítica}

\subsubsection{Descripción}

La facies FsR se compone de fangolitas arenosas a gruesas con ondulas de fango (Fig. 7A). La laminación ondulítica es asimétrica y está representada por
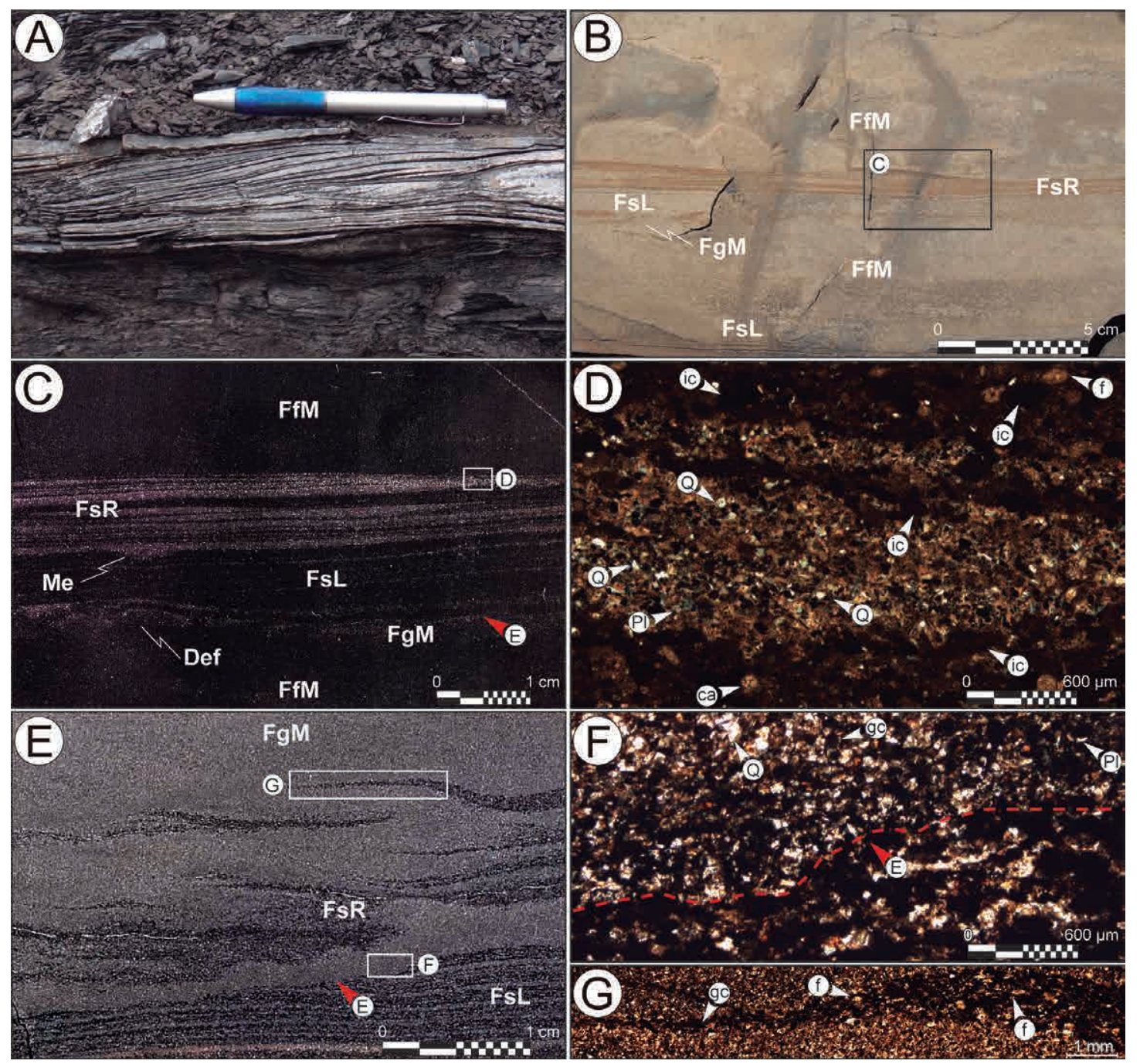

FIG. 7. Facies FsR (fangolitas arenosas con laminación ondulítica). A. Ondulas de fango grueso detrítico asociadas a flujos de fango unidireccionales (afloramiento sector Arroyo Mulichinco; escala: lapicera, $14 \mathrm{~cm}$ ). B. FsR en superficie externa de concreción carbonática (afloramiento sector Río Neuquén). C. Láminas de sotavento de bajo ángulo en un corte pulido de la muestra RN-03 tomada en B. Marcas de erosión (Me) asociadas a la base de FsR. D. Detalle de las láminas de sotavento exhibidas en $\mathrm{C}$, las cuales muestran una composición mixta constituida por láminas intraclásticas (ic) oscuras tamaño arena muy fina con calciesferas (ca), intercaladas con láminas detríticas de color claro integradas por clastos de cuarzo (Q) y plagioclasa (Pl) tamaño fango grueso-arena muy fina. E-F-G. Laminación ondulítica constituida principalmente por granos arcillosos compuestos (gc). Los granos compuestos podrían interpretarse como intraclastos provenientes de la erosión del fondo subyacente compuesto por FsL. Nótese, asimismo, la presencia de foraminíferos (f) como constituyentes de la facies FsR (muestra RN-01). 
láminas de sotavento de bajo ángulo (Fig. 7A, B, C y D), con excepciones menores donde se preservan las caras de barlovento (Fig. 7E). Esta facies suele disponerse en base erosiva (Fig. 7E y F), a veces con marcas de erosión y estructuras de deformación asociadas (Fig. 7C). En cuanto a su composición, las láminas de sotavento pueden estar integradas por clastos de cuarzo y plagioclasa tamaño fango grueso a arena muy fina (Fig. 7D) o eventualmente por granos compuestos (gc) que consisten en agregados arcillosos tamaño arena muy fina a fina (Fig. 7F y G). El término granos compuestos se emplea en el sentido de Lazar et al. (2015b) para aquellos casos donde no es posible discriminar petrográficamente el origen de los agregados de arcilla.

Interpretación. La laminación ondulítica que define a la facies FsR es equivalente a las ondulas de fango generadas a partir de ensayos de laboratorio en canaletas (Schieber et al., 2007). Por lo tanto, el origen de la facies FsR se relaciona con la acción de procesos tractivos en flujos de fango unidireccionales. En contraste con FgM, el desarrollo de FsR estaría vinculado con flujos de fango diluidos con una concentración sedimentaria relativamente baja $(<6,9 \%$, Baas et al., 2011). De esta manera, los materiales más gruesos (limo, intraclastos, flóculos de arcillas, etc.) que decantan desde la nube de suspensión en un flujo turbulento diluido adquieren un comportamiento hidráulico semejante a partículas de arena muy fina, y son transportados por tracción a la base del flujo (Schieber et al., 2007, 2013). Las evidencias sedimentológicas encontradas sugieren que, durante la migración de las ondulas de fango, la relación tracción/decantación ( $\mathrm{t} / \mathrm{d}$ ) de los flujos asociados habría sido fluctuante, y habría condicionado la preservación de las láminas de barlovento y la morfología de las ondulas, así como también la composición de las láminas.

Al igual que en la facies FgM, la presencia de un contacto basal erosivo mostraría que inicialmente estos flujos de fango habrían sido capaces de erosionar el fondo fangoso, incorporando el material intracuencal erosionado a su carga sedimentaria, y eventualmente transportarlo por tracción (Fig. 7G). Ensayos de laboratorio en canales artificiales han comprobado que, a una profundidad de $5 \mathrm{~cm}$, un flujo de fango con una velocidad de $15-30 \mathrm{~cm} / \mathrm{s}$ puede transportar arcillas floculadas (y/o intraclastos arcillosos, fango calcáreo) como carga tractiva, y así dar lugar a la formación y migración de ondulas de fango (Schieber et al., 2007; Schieber y Southard, 2009; Schieber y Yawar, 2009; Schieber et al., 2013).

\subsection{Facies FsL: fangolitas arenosas con laminación paralela}

\subsubsection{Descripción}

Esta facies se compone de fangolitas arenosas a gruesas finamente laminadas (Fig. 8A). Por lo general, la facies FsL se presenta en forma neta/erosiva (Fig. 8B y C), y está definida por una laminación fina caracterizada por láminas planares continuas dispuestas en forma paralela (Fig. 8C). Composicionalmente, dicha facies es semejante a la facies FsR (Fig. 7), caracterizada por una alternancia milimétrica de láminas de fangolitas medias a gruesas compuestas por fango detrítico extracuencal (Fig. 8E), y por láminas oscuras de fangolitas arenosas compuestas en su mayoría por intraclastos y calciesferas de origen intracuencal (Fig. 8D, E y F).

Interpretación. La laminación milimétrica que caracteriza a la facies FsL está relacionada con una decantación selectiva de materiales finos transportados en suspensión turbulenta en flujos de fango. El hecho de que esta facies exhiba una diferencia composicional tan marcada entre láminas de fangolitas gruesas detríticas y fangolitas arenosas intraclásticas parece estar asociado a un fenómeno de competencia hidráulica entre las partículas. Se interpreta que el origen de las variaciones rítmicas en el tamaño del grano común a la facies FsL podría estar asociado a flujos de larga duración sujetos a ligeras fluctuaciones en su velocidad y concentración sedimentaria (Otharán y Zavala, 2018; Otharán et al., 2018b).

Suponiendo que se parte de un flujo de fango con una velocidad inicial mayor a la velocidad crítica para la acumulación de fango grueso-arenoso $\left(\mathrm{V}_{\mathrm{f}}\right.$ (Velocidad de flujo $)>\mu_{\mathrm{FG}}$ (Velocidad crítica de acumulación de fango grueso)) y menor que la velocidad crítica de erosión de sustratos fangosos en estado soposo $\left(\mathrm{V}_{\mathrm{f}}<\mu_{\text {erosion }}\right.$ (Umbral de erosión de sustratos fangosos)), podrá ocurrir:

- $\mathrm{Si}$ el flujo con $\mathrm{V}_{\mathrm{f}}>\mu_{\mathrm{FG}}<\mu_{\text {erosión }}$ experimenta una importante aceleración, logrará vencer la velocidad crítica de erosión $\left(\mathrm{V}_{\mathrm{f}}>\mu_{\text {erosión }}\right)$, por lo cual ocurrirá una erosión parcial del sustrato.

- $\quad$ Si en cambio el mismo flujo con $\mathrm{V}_{\mathrm{f}}>\mu_{\mathrm{FG}}<\mu_{\text {erosión }}$ sufre una pérdida de velocidad, entrará al campo de 


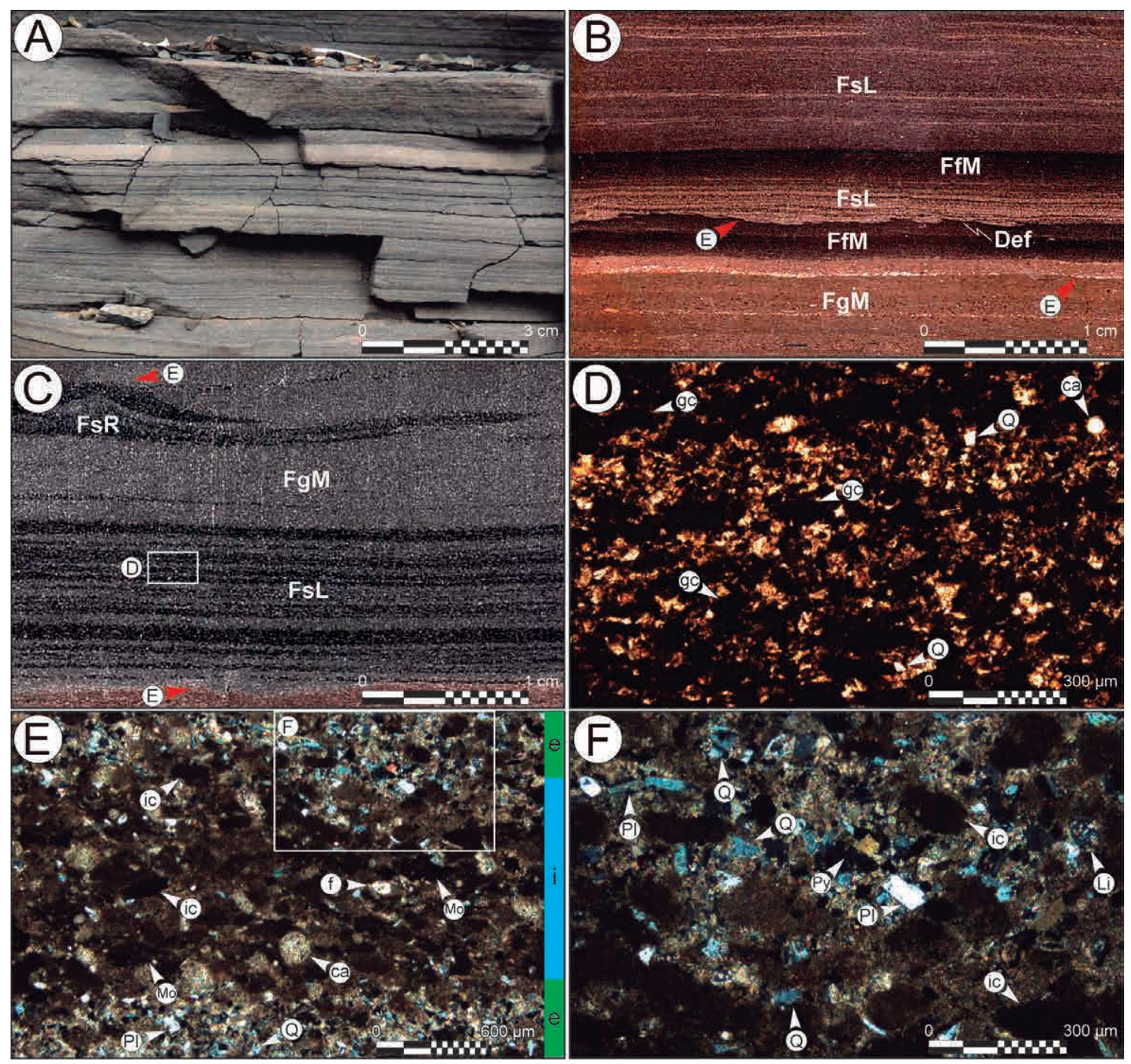

FIG. 8. Facies FsL (fangolitas arenosas con laminación paralela). A. Laminación milimétrica caracterizada por la alternancia de láminas de fangolitas gruesas detríticas y fangolitas arenosas intraclásticas (afloramiento sector Arroyo Mulichinco). B. FsL dispuesta directamente sobre una superficie de erosión con estructuras de deformación asociadas (Def). Nótese el pasaje transicional entre FsL y FfM sobreyacente (muestra TC-07). C-D. FsL compuesta por una alternancia de láminas de granos arcillosos compuestos (gc) y láminas detríticas compuestas por clastos de cuarzo (Q) tamaño fango grueso y material intracuencal (calciesferas, ca) en forma subordinada (muestra RN-02). E-F. Alternancia de láminas detríticas extracuencales (e), compuestas por clastos de cuarzo $(\mathrm{Q})$, plagioclasa $(\mathrm{Pl})$ y fragmentos líticos subordinados $(\mathrm{Li})$, y láminas intracuencales (i) representadas principalmente por intraclastos de arcilla (ic), calciesferas (ca), foraminíferos (f) y posibles agregados de materia orgánica amorfa (Mo) (muestra RN-03).

acumulación de fango grueso $\left(\mathrm{V}_{\mathrm{f}}<\mu_{\mathrm{FG}}\right)$, por lo cual ocurrirá una decantación de fango grueso detrítico, y se generará una lámina de fangolita gruesa. Por otro lado, las láminas oscuras compuestas por intraclastos y calciesferas, si bien presentan un tamaño de grano significativamente mayor al de los granos detríticos, se acumularían bajo condiciones de menor energía, dado que su peso específico es significativamente menor. De esta manera, conforme disminuye la concentración de materiales detríticos el flujo pierde velocidad de manera progresiva, hasta finalmente entrar en el campo de acumulación de fangolitas arenosas intraclásticas. 
- Si este mismo flujo de baja velocidad sufre una rápida e importante aceleración hasta superar la velocidad crítica de acumulación de fango grueso detrítico $\left(\mathrm{V}_{\mathrm{f}}>\mu_{\mathrm{FG}}\right)$, se producirá un breve período de no depositación extendido hasta que la velocidad de flujo se encuentre por debajo del umbral de transporte de fango grueso. Una vez por debajo de este umbral, comenzará nueva-mente la decantación de partículas de fango grueso.

\subsection{Facies FfM: fangolitas finas macizas}

\subsubsection{Descripción}

Esta facies se compone por fangolitas finas $(<8 \mu \mathrm{m})$ a medias $(8-32 \mu \mathrm{m})$ macizas, de composición arcillosa. Por lo general la facies FfM se dispone en base transicional sobre facies FgM o FsL, y genera depósitos enriquecidos en materia orgánica (Fig. 9A, B y C), aunque podría presentarse en base neta (Fig. 9D). Petrográficamente se reconoce la presencia de material bioclástico intracuencal (calciesferas en conjunto con agregados de materia orgánica), restos vegetales y pirita, todos dispuestos en forma diseminada en una matriz de fango fino (Fig. 9C, E y F).

Interpretación. Los materiales que la componen y el carácter macizo de sus depósitos sugieren una depositación relativamente rápida de materiales finos contenidos en flujos de fango de baja velocidad $\left(\mathrm{V}_{\mathrm{f}}<\mu_{\mathrm{FF}}\right)$. Es probable que esta facies represente el último estadio evolutivo de flujos de fango que ya han depositado su carga sedimentaria más gruesa (fango grueso detrítico, agregados de arcillas floculadas, intraclastos arcillosos, etc.), transportando solo los remanentes finos más livianos (fango fino rico en materia orgánica y microfósiles). La elevada concentración de arcillas propia de la facies FfM sugiere una transformación de flujo, dado que la cohesión interna de las partículas de arcilla habría favorecido un aumento en la viscosidad de flujo y una disminución significativa en la turbulencia (Baas et al., 2009, 2011). A esta altura, los flujos asociados se desplazarían a velocidades muy bajas hasta alcanzar su zona terminal donde finalmente se extenuarían por completo. No obstante, existen casos donde la facies FfM no se encuentra desarrollada al techo de las capas, sino que puede pasar transicionalmente a facies FgM (Figs. 5A, B y $6 \mathrm{~B})$, lo cual se relaciona con fluctuaciones de flujo en flujos de fango de larga duración.

\section{Asociación de facies}

Los depósitos de flujos de fango a menudo se disponen en capas de fangolitas gradadas de espesor centimétrico separadas por contactos erosivos/netos que definen períodos de erosión/no depositación (Fig. 5). Durante este período se interpreta que la velocidad del flujo se encontraría por encima del umbral crítico para la acumulación de fango grueso $\left(\mathrm{V}_{\mathrm{f}}>\mu_{\mathrm{FG}}\right)$.

Una vez que el flujo comienza su etapa de desaceleración, su carga sedimentaria se deposita en forma gradada $\left(\mathrm{V}_{\mathrm{f}}<\mu_{\mathrm{FG}}\right)$. Internamente, los depósitos asociados pueden presentar un arreglo macizo (FgM, FfM) o laminado (FsL, FsR), lo cual está directamente relacionado con variaciones en la velocidad, la turbulencia y la concentración sedimentaria del flujo (Baas et al., 2011; Otharán y Zavala, 2018; Otharán et al., 2018a). Por lo general, a mayor velocidad de flujo mayor turbulencia, lo cual provoca un aumento en la capacidad y competencia de flujo, y favorece un incremento en la concentración sedimentaria y el tamaño del grano de la carga en suspensión turbulenta. Por lo tanto, la velocidad del flujo controla la velocidad de decantación de la carga en suspensión turbulenta y condiciona el desarrollo de las diferentes facies reconocidas.

Dentro de las facies laminadas, se entiende que FsR requiere mayores velocidades de flujo que FsL, dado que la primera involucraría un transporte por tracción de las partículas a la base del flujo (Schieber et al., 2007; Lazar et al., 2015b). De esta manera, la carga sedimentaria más gruesa que colapsa desde la nube de suspensión sería eventualmente transportada por tracción a la base del flujo turbulento. Por otro lado, se interpreta que el desarrollo de FsL podría estar asociado a flujos de fango de menor velocidad, donde habría predominado un mecanismo de colapso selectivo de las partículas transportadas en suspensión turbulenta, y habría generado depósitos finamente laminados (Fig. 10).

Dentro de las facies macizas, el desarrollo de la facies FgM parece estar asociado a flujos con mayor concentración de sedimentos (Fig. 10). Su origen se relaciona con un colapso relativamente rápido de la carga sedimentaria transportada en suspensión turbulenta, lo cual habría inhibido el desarrollo de estructuras sedimentarias, y habría generado depósitos macizos (Ichaso y Dalrymple, 


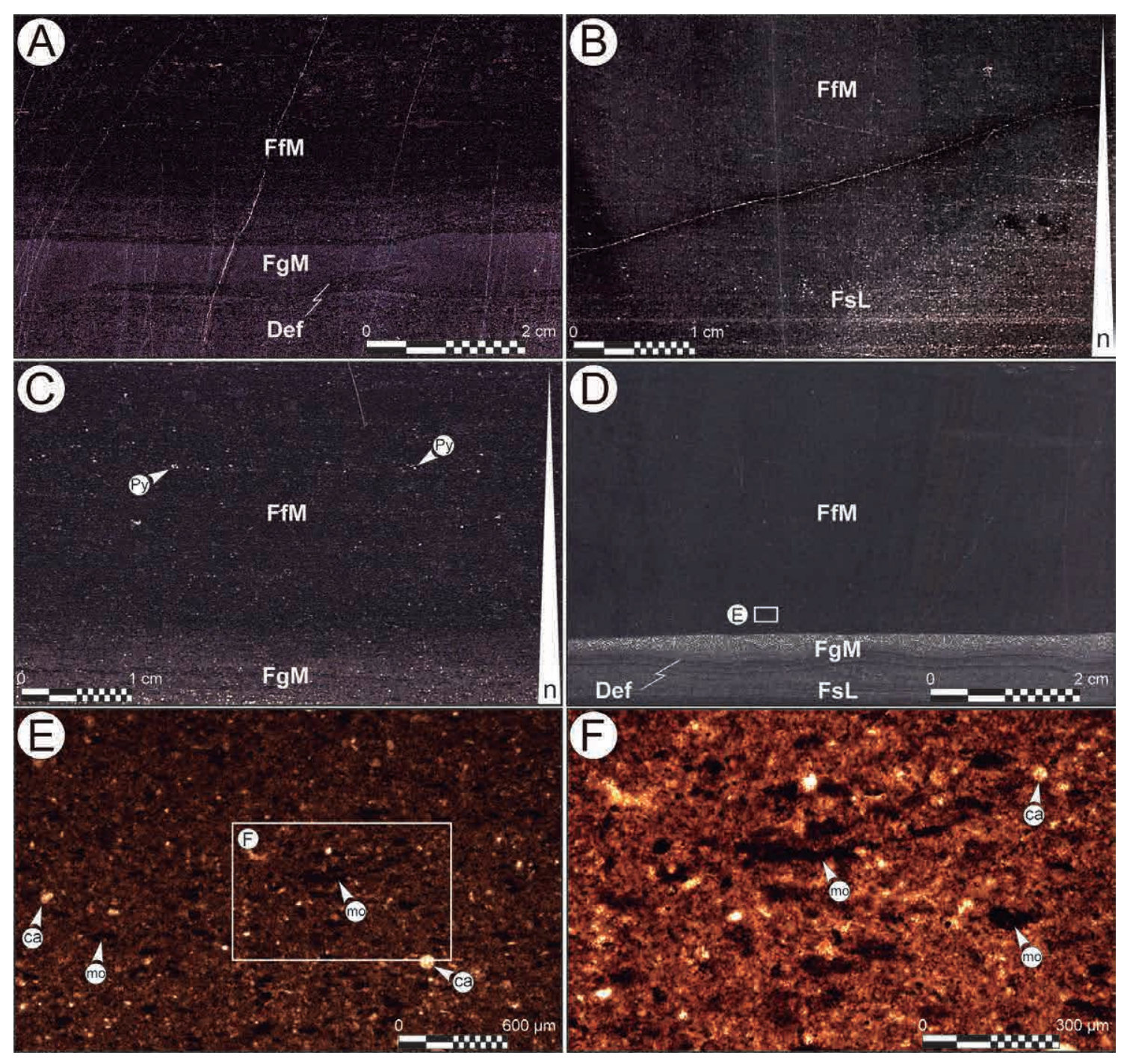

FIG. 9. Facies FfM (fangolitas finas macizas). A-B. Fangolitas finas macizas bituminosas (muestras AM-02 y TC-08, respectivamente). Esta facies comúnmente se dispone en forma transicional sobre otras facies y genera depósitos granodecrecientes (ver triángulo en b, n: gradación normal). C. Pasaje transicional de FgM a FfM (ver triángulo, n: gradación normal). Presencia de pirita (Py) diseminada (muestra AM-03). D-E-F. Fangolitas finas detríticas con abundante contenido de materia orgánica en forma de agregados oscuros (muestra AM-01). Presencia subordinada de calciesferas (ca) en forma diseminada, y posibles agregados de materia orgánica amorfa (Mo).

2009; Zhang et al., 2017). En aquellos casos donde la facies FgM conforma capas normalmente gradadas, su origen se relaciona con una disminución gradual de la velocidad y turbulencia del flujo (Fig. 5A y B). Por el contrario, cuando esta facies se dispone en forma transicional sobre la facies FfM, su origen estaría asociado a un aumento en la competencia del flujo debido a un incremento de su velocidad (Figs. 5D y 6B).
Por último, la facies FfM estaría vinculada con flujos de fango compuestos principalmente por fango fino $(<8 \mu \mathrm{m})$, material calcáreo intracuencal y materia orgánica en suspensión turbulenta. La acumulación de la carga fina residual habría sido posible solo bajo condiciones de muy baja velocidad de flujo una vez que toda la carga sedimentaria más gruesa ha sido depositada (Fig. 10). El aumento de la viscosidad de flujo inducido por la creciente cohesión interna de 


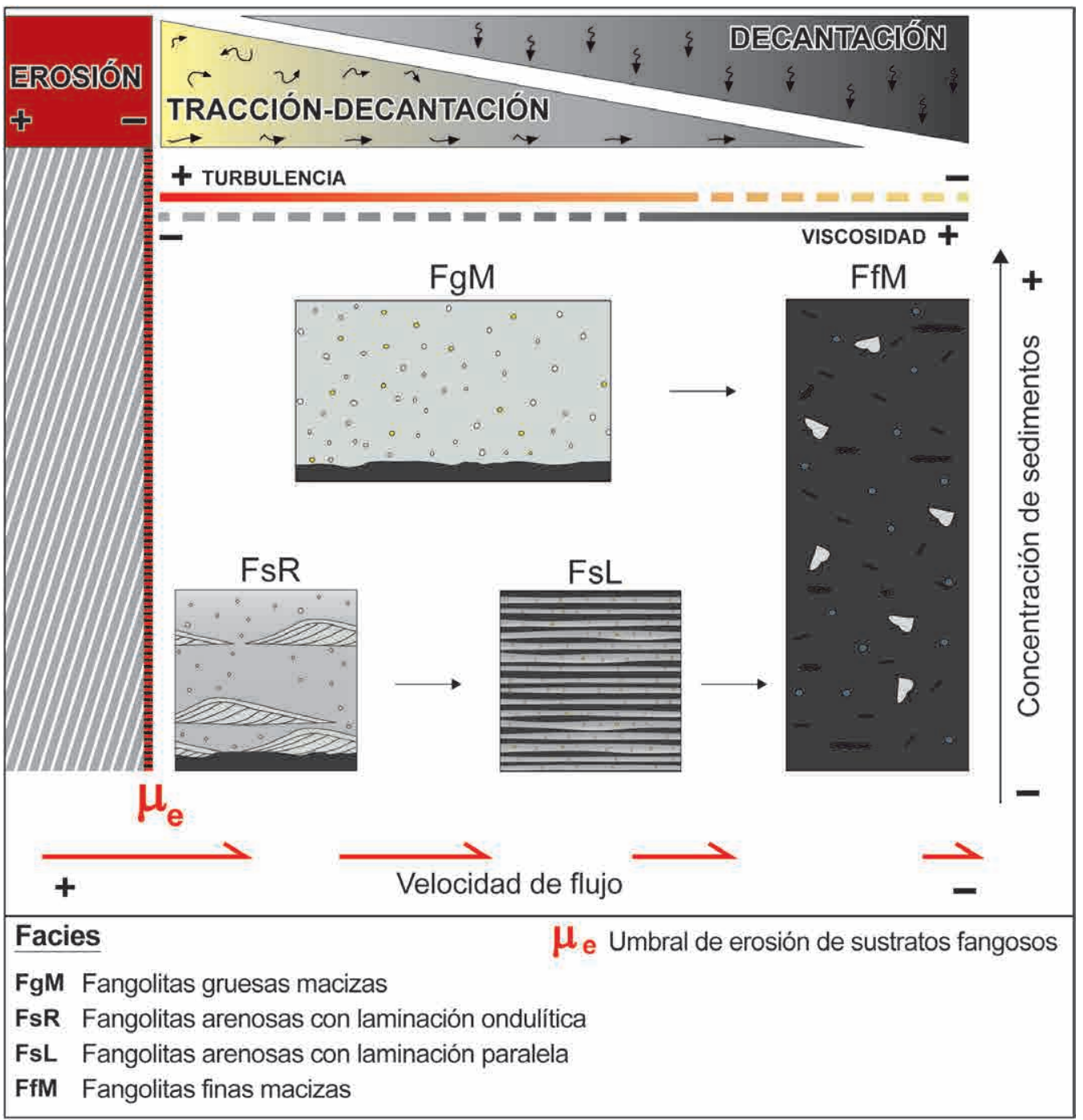

FIG. 10. Relación entre las diferentes facies asociadas a flujos de fango en función de la velocidad de flujo y de la concentración de sedimentos del flujo.

las partículas arcillosas que componen el fango fino residual (Fig. 9E) habría favorecido el colapso de la carga sedimentaria remanente, sin posibilidad de un eventual transporte por tracción (Baas et al., 2009, 2011). La rápida acumulación de la facies FfM habría permitido alcanzar un soterramiento rápido y efectivo de fango fino y agregados de materia orgánica (Fig. 9E y F).

\subsection{Origen de los flujos de fango}

Existen básicamente 4 mecanismos principales para el origen de flujos de fango (Lazar et al., 2015b):
1) corrientes de fondo (corrientes contorníticas), 2) flujos densos desencadenados durante eventos de tormenta en ambientes de rampa/plataforma, 3) flujos turbidíticos intracuencales asociados a desestabilizaciones del talud, y 4) flujos hiperpícnicos fangosos asociados a descargas directas de ríos en crecida. Por lo general, su diferenciación en el registro fósil suele ser una tarea compleja y, si bien existen aproximaciones que caracterizan individualmente a los depósitos asociados, hasta el momento no existe un modelo de facies definitivo para cada uno de estos procesos (facies genéticas). 
Esto se debe a que gran parte de lo que se conoce actualmente acerca de corrientes de densidad proviene de estudios en depósitos granulométricamente más gruesos (Bouma, 1962; Reineck y Singh, 1971; Aigner, 1982; Mutti, 1992; Stow y Mayall, 2000; Mulder et al., 2003; Zavala et al., 2006; Mulder y Chapron, 2011, entre otros), mientras que los estudios enfocados al análisis de depósitos de flujos de fango son recientes (Soyinka y Slatt, 2008; Bhattacharya y MacEachern, 2009; Schieber et al., 2010; Wilson y Schieber, 2014, 2015; Schieber, 2016), por lo que aún existen más incertidumbres que certezas (Sorby, 1908; Schieber, 2011).

El origen de las facies mixtas reconocidas en los depósitos analizados en esta contribución podría estar asociado a flujos hiperpícnicos fangosos originados durante períodos húmedos de precipitaciones extremas que dan lugar a grandes inundaciones (Mutti et al., 1996), y generan flujos casi estacionarios de larga duración (semanas/ meses, Zavala et al., 2011; Zavala y Arcuri, 2016). La composición mixta de los depósitos podría asociarse a flujos de fango de origen extracuencal (cargados de materiales detríticos y restos vegetales) que al ingresar en el medio marino habrían producido una erosión parcial del fondo fangoso, e incorporado aquellos materiales intracuencales disponibles a su carga sedimentaria extracuencal (intraclastos arcillosos, microfósiles, agregados de materia orgánica, etc.).

Los flujos hiperpícnicos casi estacionarios permiten explicar de manera coherente la recurrencia vertical de facies observada en los depósitos estudiados, así como también la común aparición de depósitos granocrecientes y estructuras de erosión internas en un mismo depósito. Estos rasgos sedimentarios se relacionan con fluctuaciones en la velocidad y concentración sedimentaria de un flujo hiperpícnico sostenido (fluctuaciones de flujo), lo cual está controlado por variaciones en la descarga del sistema fluvial asociado (Nakajima, 2006; Zavala et al., 2006; Soyinka y Slatt, 2008). De esta manera, cuanto mayor sea la descarga proveniente de sistemas fluviales en crecida, mayor será la velocidad de los flujos hiperpícnicos asociados. Lo anterior se ve reflejado en una recurrencia vertical de facies con tendencia granocreciente/ granodecreciente (Fig. 11A) o eventualmente estructuras de erosión internas en un mismo depósito (Fig. 12), lo que evidencia una mayor capacidad y/o competencia de flujos hiperpícnicos sostenidos. De esta manera, disposiciones de facies con tendencia granodecreciente se asociarían a una disminución en la velocidad de flujo (desaceleración de flujo), mientras que secuencias de facies con tendencia granocreciente sugieren un aumento en la velocidad de flujo (aceleración de flujo, Fig. 11B).

Esta característica básica permitiría diferenciar los depósitos asociados a flujos hiperpícnicos fangosos casi estacionarios (de larga duración, Fig. 11) de aquellos asociados a eventos de tormenta y flujos turbidíticos intracuencales, los cuales son de carácter episódico, suelen tener una corta duración, y producen depósitos granodecrecientes. Sin embargo, durante los picos máximos de descarga, la velocidad de flujo $\left(\mathrm{V}_{\mathrm{f}}\right)$ puede llegar a vencer el umbral de erosión $\left(\mathrm{m}_{\text {erosión }}\right)$ de fondos fangosos $\left(\mathrm{V}_{\mathrm{f}}>\mu_{\text {erosión }}\right)$, generando erosión y omisión parcial de facies previamente depositadas (Fig. 12). En estos casos, la distinción entre depósitos asociados a flujos hiperpícnicos casi estacionarios y flujos episódicos es mucho más compleja (Mulder et al., 2003; Bhattacharya y MacEachern, 2009; Wilson y Schieber, 2014; Schieber, 2016), ya que las estructuras de erosión internas podrían confundirse con límites de capas (Fig. 12).

\subsection{Erosión de fondos fangosos}

Los flujos de fango son corrientes de turbidez de baja densidad constituidas por una mezcla de agua y materiales finos transportados en suspensión turbulenta. Los depósitos asociados a menudo presentan base erosiva, lo cual demuestra que estos flujos pueden alcanzar velocidades suficientes para erosionar fondos fangosos $\left(\mathrm{V}_{\text {flujo }}>\mu_{\text {erosion }}\right)$. Este proceso favorece la incorporación de los materiales erosionados a la carga sedimentaria del flujo. De esta manera, un flujo de fango con una composición inicial A que atraviesa y erosiona un fondo fangoso de composición $\mathrm{B}$, tendrá una composición final AB. En el caso de flujos hiperpícnicos fangosos, el resultado final será una composición mixta de material extra e intracuencal (EI, Fig. 8E y F).

Es necesario recordar que el grado de erosión de un fondo fangoso es directamente proporcional al contenido relativo de agua que presenta el sustrato (Potter et al., 1980). Por lo tanto, para un mismo flujo será más simple erosionar un fondo soposo saturado de agua que uno en estado firme. Por su parte, en presencia de fondos cohesivos hidroplásticos 


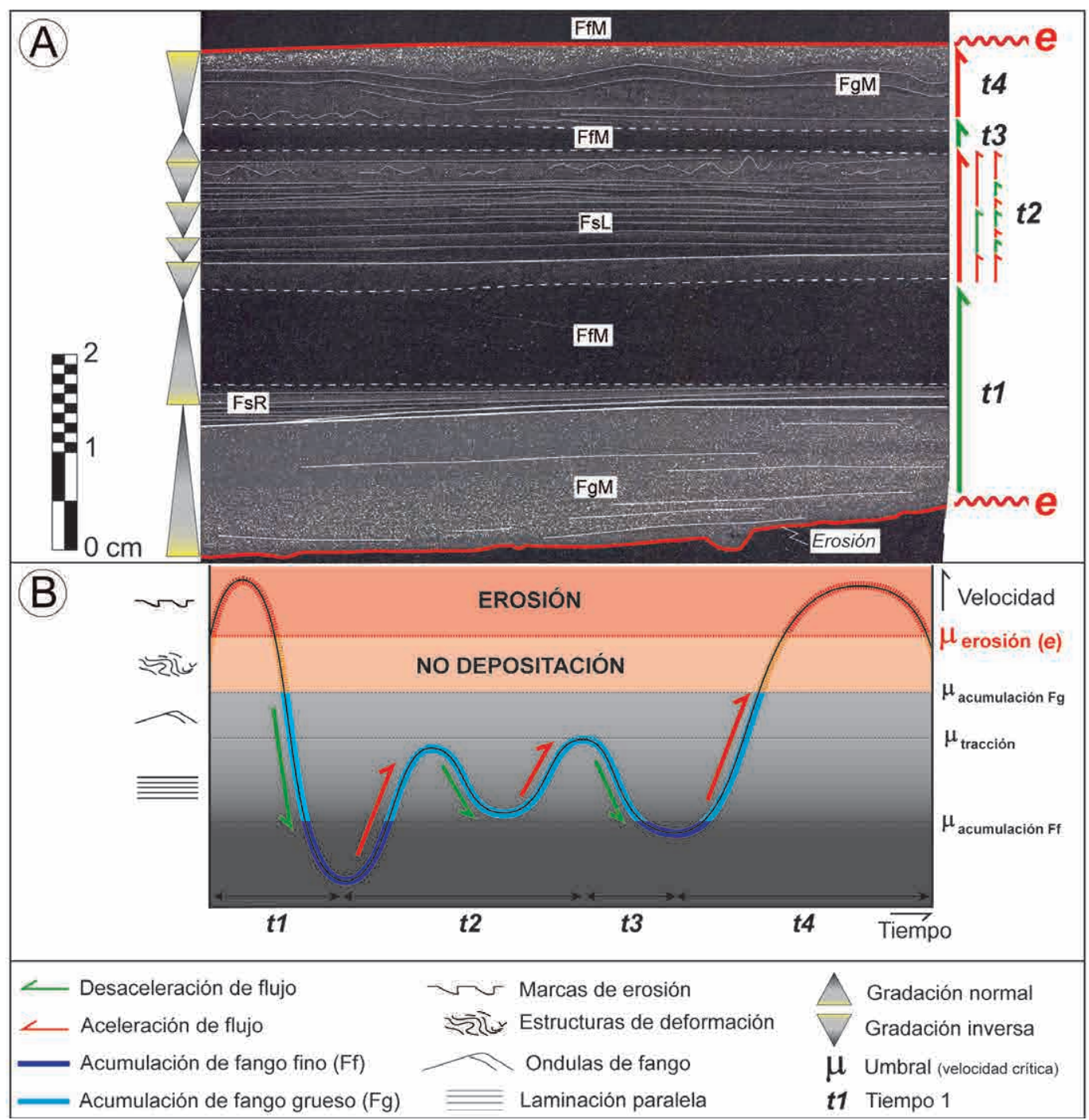

FIG. 11. Depósitos sedimentarios asociados a flujos de fango casi estacionarios. A. Depósitos granodecrecientes/granocrecientes asociados a fluctuaciones en la velocidad de flujos hiperpícnicos fangosos (muestra AM-01). La recurrencia vertical de facies con pasajes transicionales entre sí sugiere cambios en las propiedades hidrodinámicas de los flujos asociados. B. Explicación de los depósitos con tendencia granocreciente/granodecreciente a partir de fluctuaciones en la velocidad de un flujo hiperpícnico sostenido (basado en Zavala et al., 2006). Este gráfico muestra la relación velocidad-tiempo en un flujo casi estacionario. Se interpreta que las sucesivas fluctuaciones en la velocidad de flujo (aceleraciones-desaceleraciones de flujo) a través del tiempo (t1-t4) habrían condicionado el desarrollo de las diferentes facies y la gradación interna de los depósitos asociados.

(en estado soposo), el paso de un flujo de fango puede producir una deformación del sustrato por el que se desplaza y generar estructuras de deformación (Sanders, 1965; Schieber, 1998; Potter et al., 2005). De acuerdo con Schieber (1998), se requieren velocidades de al menos $150 \mathrm{~cm} / \mathrm{s}$ para producir estructuras deformacionales en un sustrato fangoso con $70 \%$ de porosidad (Einsele et al., 1974). La común ocurrencia de estructuras deformacionales por debajo de bases erosivas sugiere un origen vinculado al mismo proceso erosivo, en donde previo a la erosión del sustrato soposo ocurriría una deformación parcial del fondo (Figs. 5C, 7C, 8B, 9A y D). Por otro lado, cuando en lugar de estructuras de deformación se reconocen marcas de erosión asociadas a las bases erosivas, se asume que se trata de una erosión de un sustrato 


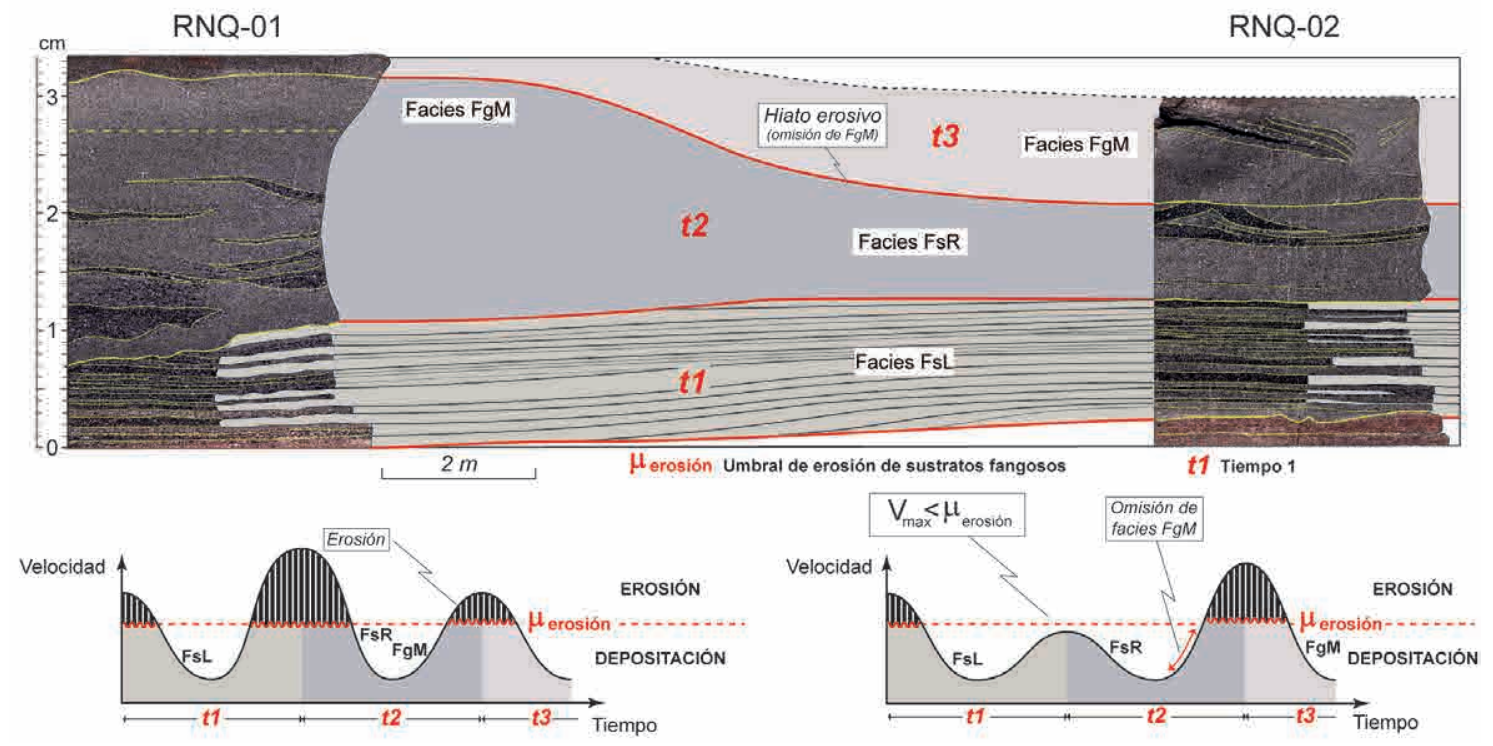

FIG. 12. Evidencias de fluctuaciones en la velocidad (v) de un flujo hiperpícnico fangoso de larga duración (flujos casi estacionarios). Las aceleraciones en la velocidad de flujo generadas durante los picos de descarga fluvial pueden causar erosión interna en un mismo depósito $\left(\mathrm{V}_{\text {flujo }}>\mu_{\text {erosión }}\right)$, con la consecuente omisión parcial de facies previamente depositadas.

fangoso en estado firme, no saturado (Figs. 6D, E, 7E, F y 8C).

De esta manera, según la magnitud y duración del evento erosivo, podrán encontrarse diferentes tipos de estructuras de erosión asociadas. Si se considera un fondo fangoso tipo (compuesto por una capa superficial de fango saturado o zona saturada, y una capa más profunda de fangos compactados no saturados, Fig. 13A y B) sobre el cual comienza a desplazarse un flujo de fango sostenido, podría ocurrir lo siguiente:

En una primera etapa, a medida que el flujo se desplaza por el fondo, ejerce una fuerza de arrastre que resulta en una deformación incipiente de los materiales que componen el sustrato (Fig. 13C).

Asociado al avance de la deformación ocurre el desarrollo de estructuras deformacionales, al mismo tiempo que el flujo comienza a erosionar el sustrato soposo (Fig. 13D y E).

$\mathrm{Si}$ el evento erosivo perdura en el tiempo $\left(\mathrm{V}_{\text {flujo }}\right.$ $\left.>\mu_{\text {erosión }}\right)$, se puede alcanzar a remover por completo el sustrato soposo hasta profundidades donde los sedimentos se encuentran en estado firme.

Si la erosión continúa, ahora sobre un sustrato en estado firme (Fig. 13F), puede ocurrir una separación de flujo bajo condiciones severas de velocidad y generar vórtices que erosionan el fondo y producen marcas de erosión (Dżulyński y Sanders, 1962; Sanders, 1965).
Este razonamiento sigue las ideas de Vail et al. (1992) y Schieber (1998), quienes relacionan la presencia de marcas de erosión con eventos de alta energía que habrían removido al menos la capa superficial de fango saturado hasta alcanzar profundidades donde los materiales se encuentran en estado firme (Fig. 6A). Sin embargo, existen otras explicaciones posibles, por ejemplo, puede ocurrir que la capa superficial de fango soposo se encuentre eventualmente ausente debido a un período de muy baja tasa de acumulación que inhibe su desarrollo. En este caso, el pasaje de un flujo de fango con capacidad erosiva podría generar marcas de erosión en un fondo fangoso inicialmente en estado firme. Por lo tanto, se debe tener en cuenta que la presencia de marcas de erosión no siempre indica una erosión profunda de fondos fangosos.

\section{Discusión}

Durante mucho tiempo los depósitos de grano fino que componen la Formación Vaca Muerta fueron asociados a procesos de decantación hemipelágica en un medio marino de offshore caracterizado por una columna de agua estratificada y fondos disóxicosanóxicos (Gulisano et al., 1984; Legarreta y Uliana, 1991, entre otros). Sin embargo, recientes estudios 


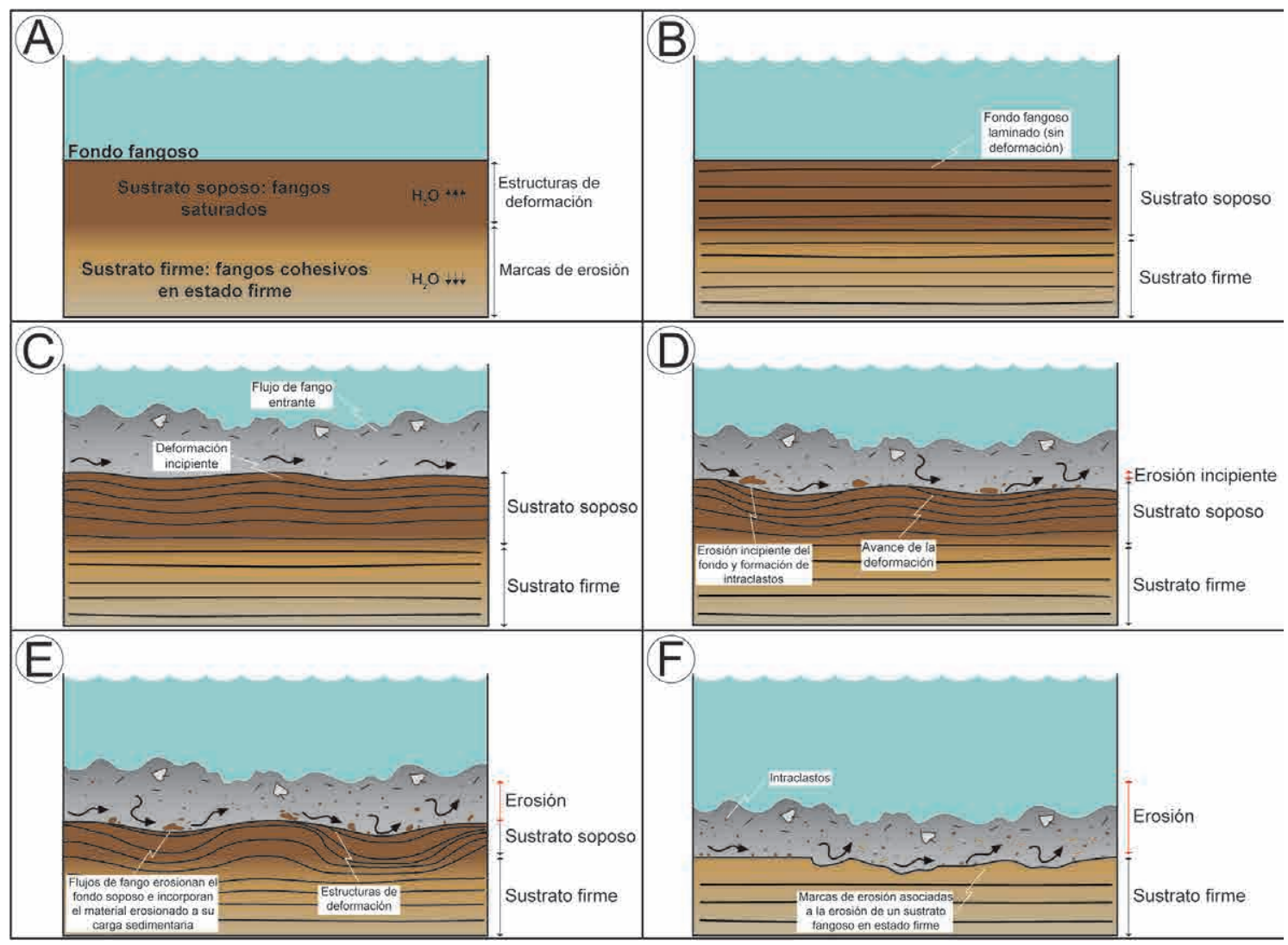

FIG. 13. Erosión de fondos fangosos por acción de flujos de fango. A-B. Fondo fangoso laminado, compuesto por una zona superior saturada en agua (zona soposa) y una inferior caracterizada por fangos laminados compactados (zona firme). C. El pasaje de un flujo de fango entrante ocasiona una deformación incipiente de los fangos laminados que componen el fondo fangoso saturado. D. En presencia de flujos de fango sostenidos, el flujo continúa actuando sobre el fondo fangoso, lo cual favorece un incremento en el grado de deformación, y asimismo comienza a ocurrir una erosión incipiente del fondo fangoso saturado. E. La deformación y erosión del fondo fangoso siguen avanzando, dejando una zona saturada remanente de escaso espesor. F. Si el flujo de fango sostenido mantiene su velocidad por encima de la velocidad crítica para erosionar fondos fangosos saturados, podrá remover por completo la zona saturada, y alcanzar la zona firme. En fondos fangosos firmes, la erosión dependerá de la velocidad de flujo.

sedimentológicos han demostrado que parte de los depósitos finos que constituyen esta unidad se habrían acumulado bajo condiciones considerablemente más energéticas que lo antiguamente previsto (Kietzmann et al., 2008, 2011, 2014a, b, 2016; González Tomassini et al., 2014; González et al., 2016; Reijenstein et al., 2017, entre otros).

Por otro lado, si bien las zonas internas de la Cuenca Neuquina habrían sido propicias para el almacenamiento y la preservación de la materia orgánica (Kietzmann et al., 2016), aún no se termina de comprender la razón por la cual los depósitos con mayor riqueza orgánica se encuentran generalmente asociados a áreas depocentrales. Por lo general, estos ambientes suelen presentar una productividad orgánica relativamente baja y, asimismo, el aporte de materia orgánica proveniente de plumas boyantes tiene un potencial de preservación muy bajo, debido al largo camino que debe recorrer a través de la extensa columna de agua (Arthur et al., 1984; Stow et al., 2001). Durante los últimos años, el desarrollo de expediciones oceanográficas en sistemas depositacionales actuales permitió obtener una mejor comprensión acerca de los mecanismos más eficaces para la transferencia de fango rico en materia orgánica hacia el interior de las cuencas oceánicas (Baudin et al., 2010, 2017a, b; Biscara et al., 2011; Stetten et al., 2015; Mignard et al., 2017). Estas contribuciones 
mencionan que los flujos gravitativos de sedimentos juegan un rol clave en la transferencia, acumulación y preservación (secuestro) de la materia orgánica en ambientes marinos de offshore.

El intervalo basal de la Formación Vaca Muerta se corresponde con zonas de bottomsets de las unidades 1 y 2 definidas por Sattler et al. (2016). Los depósitos asociados poseen hasta $8 \%$ COT, razón por la cual este intervalo es considerado uno de los principales objetivos no convencionales de la Formación Vaca Muerta (González et al., 2016). Frecuentemente, las evidencias que permiten interpretar el origen de parte de las rocas de grano fino incluidas dentro del segmento basal de la Formación Vaca Muerta, se encuentran preservadas en el interior de concreciones carbonáticas exentas de compactación, algunas de las cuales fueron estudiadas en detalle en esta contribución. El arreglo interno que exhiben estos depósitos indicaría un posible origen relacionado con flujos de fango de origen extracuencal (flujos hiperpícnicos fangosos).

De acuerdo con Mutti et al. (1996), el origen de los flujos hiperpícnicos está controlado por cambios climáticos cíclicos de diferente magnitud (ciclos de Milankovitch), los que proveen las cantidades suficientes de agua para producir inundaciones catastróficas. En particular, la Formación Vaca Muerta es un ejemplo mundialmente conocido de una sucesión rítmica caracterizada por ciclos margacaliza que responden a un control cíclico externo en la sedimentación, posiblemente inducido por cambios climáticos (Scasso et al., 2002, 2005; Kietzmann et al., 2011, 2015). Estos ciclos climáticos podrían evidenciarse en sectores internos de la cuenca como depósitos hemipelágicos (ciclos secos) rítmicamente interrumpidos por depósitos hiperpícnicos (ciclos húmedos). De esta manera, durante los períodos húmedos la tasa de denudación superficial habría aumentado al mismo tiempo que se activaban las redes de drenaje, lo que habría incrementado drásticamente el volumen de fango detrítico aportado a la cuenca (Mutti et al., 1996). Una vez alcanzada la línea de costa, la elevada concentración sedimentaria que tendrían los sistemas fluviales habría permitido vencer la densidad del agua marina y generar descargas hiperpícnicas periódicas capaces de atravesar relieves de muy baja pendiente por centenares de kilómetros (Nakajima, 2006; Soyinka y Slatt, 2008; Bhattacharya y MacEachern, 2009; Mulder y Chapron, 2011; Zavala y Arcuri, 2016).
Sin embargo, hasta el momento se desconoce el rol de los flujos hiperpícnicos en la acumulación de los sedimentos que dieron origen a las rocas incluidas en la Formación Vaca Muerta. Esto se debe principalmente a que los niveles de fangolitas están altamente compactados, lo cual produce una pérdida de resolución importante y torna complicado el análisis de procesos sedimentarios a escala centimétrica-milimétrica. Si bien los depósitos de flujos hiperpícnicos fangosos parecen estar presentes en sectores internos de la Cuenca Neuquina (localidades de Arroyo Mulichinco, Tres Chorros y Río Neuquén), es necesario aclarar que posiblemente la acumulación de la secuencia sedimentaria incluida en la Formación Vaca Muerta habría estado controlada por una interacción mutua de procesos de decantación hemipelágica y flujos de fango de distinta naturaleza (Kietzmann et al., 2014a, c, 2016; González Tomassini et al., 2014; Reijenstein et al., 2017; Otharán et al., 2018a).

Independientemente de su origen intracuencal o extracuencal, los flujos de fango habrían actuado como excelentes medios de transferencia de sedimentos finos y materia orgánica hacia zonas internas de la cuenca (Otharán et al., 2018a, b). En su trayectoria cuenca adentro, habrían sido capaces de incorporar material intracuencal en zonas proximales del sistema, retransportándolo hacia zonas distales donde finalmente se depositaría y conformaría capas gradadas (Fig. 14). De esta manera, el transporte de la materia orgánica por medio de flujos de fango habría contribuido a una depositación relativamente rápida de la misma, y habría favorecido su preservación en intervalos con alto COT.

\section{Conclusiones}

Estudios sedimentológicos realizados en concreciones carbonáticas contenidas en fangolitas bituminosas (hasta $8 \%$ COT), que constituyen la parte basal de la Formación Vaca Muerta en las áreas de Arroyo Mulichinco, Río Neuquén y Tres Chorros (unidades 1 y 2 de Sattler et al., 2016), han permitido documentar la presencia de depósitos originados a partir de flujos de fango.

El arreglo interno de estos depósitos sugiere un origen relacionado con flujos hiperpícnicos fangosos desencadenados a partir de descargas directas de ríos en crecida. En su trayectoria cuenca adentro, 


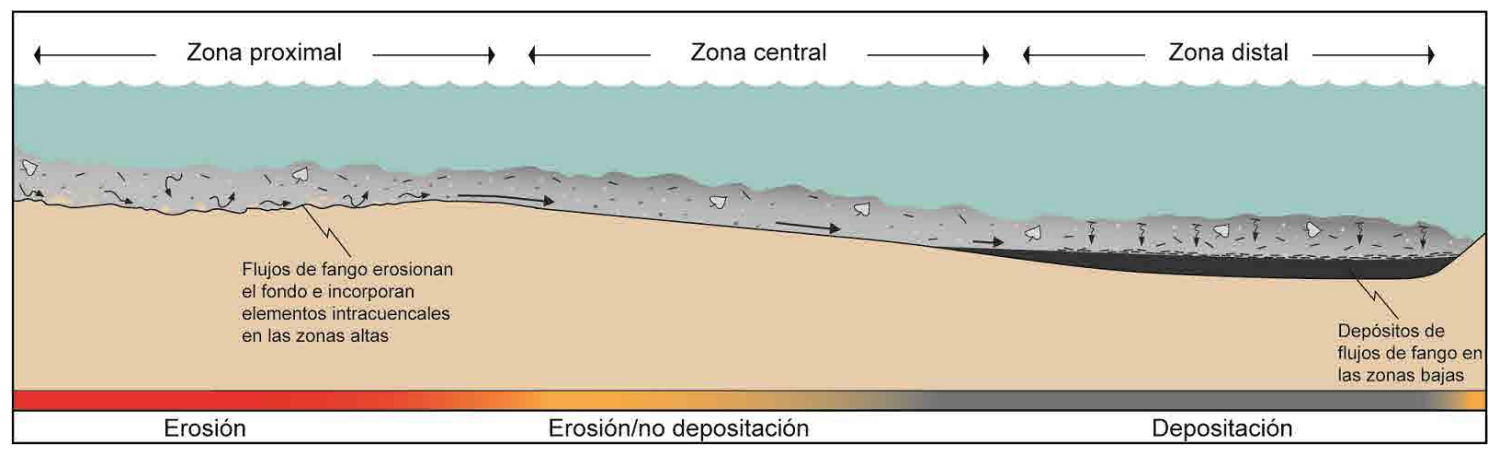

FIG. 14. Esquema evolutivo del comportamiento de los flujos de fango. En zonas proximales, los flujos de fango erosionan el fondo fangoso, e incorporan los materiales intracuencales erosionados a su carga sedimentaria. Una vez alcanzada la zona distal del sistema, los flujos depositan su carga sedimentaria en capas gradadas. Basado en Schieber et al. (2010).

los flujos hiperpícnicos cargados de fango detrítico habrían incorporado el material intracuencal disponible (incluyendo materia orgánica), y lo habrían transferido conjuntamente con su carga sedimentaria extracuencal hacia sectores más distales de la cuenca. La rápida transferencia de fango rico en materia orgánica habría permitido alcanzar un soterramiento rápido y eficiente de la materia orgánica, lo que habría evitado su potencial degradación en el fondo marino. Este proceso habría favorecido el desarrollo de depósitos con altos contenidos de COT.

Hasta el momento se desconoce la importancia de los flujos hiperpícnicos en la acumulación de los sedimentos fangolíticos que dieron origen a las rocas que constituyen la Formación Vaca Muerta. Sin embargo, el hallazgo de hiperpicnitas fangosas abre nuevas perspectivas para comprender el origen de las sucesiones de rocas de grano fino con elevado contenido de materia orgánica presentes en zonas internas de la Cuenca Neuquina. La dinámica de estos ambientes depositacionales muestra una importante complejidad, derivada de la interacción de procesos de decantación hemipelágica y flujos de fango de distinta naturaleza (eventos de tormenta, deslizamientos del talud, flujos hiperpícnicos fangosos).

\section{Agradecimientos}

Los autores agradecen al CONICET y al Departa-mento de Geología de la Universidad Nacional del Sur por el apoyo brindado. Asimismo, se reconoce la valiosa colaboración del Laboratorio de Petrotomía de la Universidad Nacional del Sur en la preparación de los cortes pulidos de roca. A Pampa Energía por permitir la publicación de los datos del perfil de Arroyo Mulichinco. Finalmente, los autores desean expresar un agradecimiento especial al editor, el Dr. W. Vivallo, y los revisores, el Dr. D. Kietzmann y la Dra. S. Elgueta, quienes contribuyeron a mejorar sustancialmente este manuscrito.

\section{Referencias}

Abouelresh, M.O.; Slatt, R.M. 2011. Shale depositional processes: Example from the Paleozoic Barnett Shale, Fort Worth Basin, Texas, USA. Open Geosciences 3 (4): 398-409. doi: 10.2478/s13533-011-0037-z.

Abouelresh, M.O.; Slatt, R.M. 2012. Lithofacies and sequence stratigraphy of the Barnett Shale in eastcentral Fort Worth Basin, Texas. American Association of Petroleum Geologists, Bulletin 96 (1): 1-22.

Aigner, T. 1982. Calcareous tempestites: storm-dominated stratification in Upper Muschelkalk limestones (Middle Trias, SW-Germany). In Cyclic and event stratification (Einsele, G.; Seilacher, A.; editors). Springer: 180-198. Berlín.

Askenazi, A.; Biscayart, P.; Cáneva, M.; Montenegro, S.; Moreno, M. 2013. Analogía entre la Formación Vaca Muerta y Shale Gas/Oil Plays de EE.UU. Society of Petroleum Engeneers (SPE): 20 p.

Arregui, C. 2014. Ciclos deposicionales de las Formaciones Quintuco y Vaca Muerta: génesis y evolución. In Congreso de Exploración y Desarrollo de Hidrocarburos, No. 9, Trabajos Técnicos 2: 189-207. Mendoza.

Arthur, M.A.; Dean, W.E.; Stow, D.A. 1984. Models for the deposition of Mesozoic Cenozoic fine-grained organic-carbon-rich sediment in the deep sea. Geological Society of London, Special Publication 15: $527-560$ 
Baas, J.H.; Best, J.L.; Peakall, J.; Wang, M. 2009. A phase diagram for turbulent, transitional, and laminar clay suspension flows. Journal of Sedimentary Research 79: 162-183.

Baas, J.H.; Best, J.L.; Peakall, J. 2011. Depositional processes, bedform development and hybrid bed formation in rapidly decelerated cohesive (mud-sand) sediment flows. Sedimentology 58: 1953-1987.

Bathurst, R.G. 1970. Problems of lithification in carbonate muds. Proceedings of the Geologists Association 81 (3): 429-440.

Baudin, F.; Disnar, J.R.; Martínez, P.; Dennielou, B. 2010. Distribution of the organic matter in the channel-levees systems of the Congo mud-rich deep-sea fan (West Africa). Implication for deep offshore petroleum source rocks and global carbon cycle. Marine and Petroleum Geology 27 (5): 995-1010.

Baudin, F.; Stetten, E.; Schnyder, J.; Charlier, K.; Martínez, P.; Dennielou, B.; Droz, L. 2017a. Origin and distribution of the organic matter in the distal lobe of the Congo deep-sea fan-A Rock-Eval survey. Deep Sea Research Part II: Topical Studies in Oceanography 142: 75-90. doi: 10.1016/j.dsr2.2017.01.008.

Baudin, F.; Martínez, P.; Dennielou, B.; Charlier, K.; Marsset, T.; Droz, L.; Rabouille, C. 2017b. Organic carbon accumulation in modern sediments of the Angola basin influenced by the Congo deep-sea fan. Deep Sea Research Part II: Topical Studies in Oceanography, 142: 64-74. doi: 10.1016/j.dsr2.2017.01.009.

Bhattacharya, J.P.; Walker, R.G. 1992. Deltas. In Facies Models: Response to sea Level Change (Walker, R.G.; James, N.P.; editors). Geological Association of Canada: 157-177. Ontario.

Bhattacharya, J.P.; MacEachern, J.A. 2009. Hyperpycnal rivers and prodeltaic shelves in the Cretaceous seaway of North America. Journal of Sedimentary Research 79 (4): 184-209.

Biscara, L.; Mulder, T.; Martínez, P.; Baudin, F.; Etcheber, H.; Jouanneau, J.M.; Garlan, T. 2011. Transport of terrestrial organic matter in the Ogooué deep sea turbidite system (Gabon). Marine and Petroleum Geology 28 (5): 1061-1072.

Boggs Jr., S. 2001. The Oceanic (Deep-Water) Environment. In Principles of sedimentology and stratigraphy (Boggs Jr., S.; editor). Prentice-Hall: 349-364. New Jersey.

Bohacs, K.M.; Lazar, O.R.; Demko, T.M. 2014. Parasequence types in shelfal mudstone strata-Quantitative observations of lithofacies and stacking patterns, and conceptual link to modern depositional regimes. Geology 42 (2): 131-134.
Bouma, A.H. 1962. Sedimentology of some Flysch deposits: a graphic approach to facies interpretation. Elsevier: 168 p. Amsterdam.

Demaison, G.J.; Moore, G.T. 1980. Anoxic environments and oil source bed genesis. Organic Geochemistry 2 (1): 9-31.

Desjardins, P.; Fantín, M.; González Tomassini, F.; Reijenstein, H.; Sattler, F.; Domínguez, F.; Kietzmann, D.; Leanza, H.; Bande, A.; Benoit, S.; Borgnia, M.; Vittore, F.; Simo, T.; Minisini, D. 2016. Capítulo 2: Estratigrafía Sísmica Regional. In Transecta Regional de la Formación Vaca Muerta (González, G.; Vallejo, D.; Desjardins, P.; González Tomassini, F.; Kietzmann, D.; Rivarola, L.; Domínguez, F.; editores). Instituto Argentino del Petróleo y Gas (IAPG): 5-22. Buenos Aires.

Dżulyński, S.; Sanders, J.E. 1962. Current marks on firm mud bottoms. Connecticut Academy of Science Transactions 42: 57-96.

Einsele, G.; Overbeck, R.; Schwarz, H.U.; Unsöld, G. 1974. Mass physical properties, sliding and erodibility of experimentally deposited and differentially consolidated clayey muds. Sedimentology 21 (3): 339-372.

Galeazzi, S.; González, G.; Santiago, M.; García, D.; Maschio, L.; González, R.; Ramírez Martínez, J. (editores). 2014. Ampliando el Horizonte Energético. In Congreso de Exploración y Desarrollo de Hidrocarburos, No. 9, Simposio de Recursos no Convencionales, Instituto Argentino del Petróleo y Gas (IAPG): 904 p. Mendoza.

González Tomassini, F.; Kietzmann, D.A.; Fantín, M.A.; Crousse, L.C.; Reijenstein, H.M. 2014. Estratigrafía y análisis de facies de la Formación Vaca Muerta en el área de El Trapial, Cuenca Neuquina, Argentina. In Congreso de Exploración y Desarrollo de Hidrocarburos, No. 9, Simposio de Recursos no Convencionales, Instituto Argentino del Petróleo y Gas (IAPG): 587-611. Mendoza.

González, G.; Vallejo, M.D.; Kietzmann, D.; Marchal, D.; Desjardins, P.; González Tomassini, F.; GómezRivarola, L.; Domínguez, R.F. (editores). 2016. Transecta regional de la Formación Vaca Muerta: Integración de sísmica, registro de pozos, coronas y afloramientos. Instituto Argentino del Petróleo y Gas (IAPG): 252 p. Buenos Aires.

Groeber, P. 1946. Observaciones geológicas a lo largo del meridiano $70^{\circ}$. 1. Hoja Chos Malal. Revista de la Sociedad Geológica Argentina 1 (3): 177-208.

Gulisano, C.A.; Gutiérrez Pleimling, A.R.; Digregorio, R.E. 1984. Esquema estratigráfico de la secuencia Jurásica del oeste de la provincia del Neuquén. In Congreso 
Geológico Argentino, No. 9, Actas 1: 236-259. San Carlos de Bariloche.

Ichaso, A.A.; Dalrymple, R.W. 2009. Tide-and wavegenerated fluid mud deposits in the Tilje Formation (Jurassic), offshore Norway. Geology 37 (6): 539-542.

Iparraguirre, J.; Zavala, C.; Arcuri, M.; Di Meglio, M.; Zorzano, A. 2016. Litho 2: Enabling the power of mobile devices and cloud computing for creating comprehensive sedimentary logs from outcrop, core and mud logging. In International Conference and Exhibition, Society of Exploration Geophysicists and American Association of Petroleum Geologists: p. 74. Barcelona. doi: 10.1190/ice2016-6349079.1.

Kietzmann, D.A.; Palma, R.M. 2011. Las tempestitas peloidales de la Formación Vaca Muerta (TithonianoValanginiano) en el sector surmendocino de la Cuenca Neuquina, Argentina. Latin American Journal of Sedimentology and Basin Analysis 18 (2): 121-149.

Kietzmann, D.A.; Palma, R.M.; Bressan, G.S. 2008. Facies y microfacies de la rampa tithoniana-berriasiana de la Cuenca Neuquina (Formación Vaca Muerta) en la sección del Arroyo Loncoche-Malargüe, provincia de Mendoza. Revista de la Asociación Geológica Argentina 63 (4): 696-713.

Kietzmann, D.A.; Martin-Chivelet, J.; Palma, R.M.; LópezGómez, J.; Lescano, M.; Concheyro, A. 2011. Evidence of precessional and eccentricity orbital cycles in a Tithonian source rock: the mid-outer carbonate ramp of the Vaca Muerta Formation, Northern Neuquén Basin, Argentina. American Association of Petroleum Geologists, Bulletin 5 (9): 1459-1474.

Kietzmann, D.A.; Ambrosio, A.L.; Suriano, J.; Alonso, S.; Vennari, V.; Aguirre-Urreta, B.; Depine, G.; Repol, D. 2014a. Análisis sedimentológico y estratigráfico secuencial de las Formaciones Vaca Muerta y Quintuco en el área de Chos Malal, Cuenca Neuquina. In Congreso de Exploración y Desarrollo de Hidrocarburos, No. 9, Trabajos Técnicos: 269-288. Mendoza.

Kietzmann, D.A.; Ambrosio, A.L.; Suriano, J.; Alonso, S.; Vennari, V.; Aguirre-Urreta, B.; Depine, G.; Repol, D. 2014b. Variaciones de facies de las secuencias basales de la Formación Vaca Muerta en su localidad tipo (Sierra de la Vaca Muerta), Cuenca Neuquina. In Congreso de Exploración y Desarrollo de Hidrocarburos, No. 9, Trabajos Técnicos: 299-318. Mendoza.

Kietzmann, D.A.; Palma, R.M.; Riccardi, A.C.; MartinChivelet, J.; López-Gómez, J. 2014c. Sedimentology and sequence stratigraphy of a Tithonian-Valanginian carbonate ramp (Vaca Muerta Formation): A misunderstood exceptional source rock in the Southern
Mendoza area of the Neuquén Basin, Argentina. Sedimentary Geology 302: 64-86.

Kietzmann, D.A.; Palma, R.M.; Llanos, M.P.I. 2015. Cyclostratigraphy of an orbitally-driven TithonianValanginian carbonate ramp succession, Southern Mendoza, Argentina: Implications for the JurassicCretaceous boundary in the Neuquén Basin. Sedimentary Geology 315: 29-46.

Kietzmann, D.A.; Ambrosio, A.L.; Suriano, J.; Alonso, M.S.; González Tomassini, F.; Depine, G.; Repol, D. 2016. The Vaca Muerta-Quintuco system (TithonianValanginian) in the Neuquén Basin, Argentina: A view from the outcrops in the Chos Malal fold and thrust belt. American Association of Petroleum Geologist, Bulletin 100 (5): 743-771.

Könitzer, S.F.; Davies, S.J.; Stephenson, M.H.; Leng, M.J. 2014. Depositional controls on mudstone lithofacies in a basinal setting: Implications for the delivery of sedimentary organic matter. Journal of Sedimentary Research 84 (3): 198-214.

Lash, G.G.; Blood, D. 2004. Geochemical and textural evidence for early (shallow) diagenetic growth of stratigraphically confined carbonate concretions, Upper Devonian Rhinestreet black shale, western New York. Chemical Geology 206 (3): 407-424.

Lazar, O.R.; Bohacs, K.M.; Macquaker, J.H.; Schieber, J.; Demko, T.M. 2015a. Integrated approach for the nomenclature and description of the spectrum of finegrained sedimentary rocks. Journal of Sedimentary Research 85 (3): 230-246.

Lazar, R.; Bohacs, K.M.; Schieber, J.; Macquaker, J.; Demko, T. 2015b. Mudstone Primer: Lithofacies variations, diagnostic criteria, and sedimentologicstratigraphic implications at lamina to bedset scale. Society for Sedimentary Geology: 204 p. Oklahoma.

Leanza, H.A. 1973. Estudio sobre los cambios faciales de los estratos limítrofes Jurásico-Cretácicos entre Loncopué y Picún Leufú, provincia del Neuquén, República Argentina. Revista de la Asociación Geológica Argentina 28 (2): 97-132.

Leanza,H.A.; Hugo, C.A.; Repol, D.; Salvarredy Aranguren, M. 2003. Miembro Huncal (Berriasiano inferior): un episodio turbidítico en la Formación Vaca Muerta, Cuenca Neuquina, Argentina. Revista de la Asociación Geológica Argentina 58 (2): 248-254.

Leanza, H.A.; Sattler, F.; Martínez, R.S.; Carbone, O. 2011. La Formación Vaca Muerta y equivalentes (Jurásico tardío-Cretácico temprano) en la Cuenca Neuquina. In Congreso Geológico Argentino, No. 18, Actas: 113-129. Neuquén. 
Legarreta, L.; Gulisano, C.A. 1989. Análisis estratigráfico secuencial de la cuenca Neuquina (Triásico superiorTerciario Inferior). In Congreso Geológico Argentino, No. 10, Actas: 221-243. Tucumán.

Legarreta, L.; Uliana, M.A. 1991. Jurassic-Cretaceous marine oscillations and geometry of backarc basin fill, central Argentine Andes. In Sedimentation, Tectonics and Eustasy: Sea level Changes at Active Plate Margins (MacDonald, D.I.; editor). International Association of Sedimentologists, Special Publication 12: 429-450. Oxford.

Legarreta, L.; Villar, H.J. 2015. The Vaca Muerta Formation (Late Jurassic-Early Cretaceous), Neuquén Basin, Argentina: Sequences, Facies and Source Rock Characteristics. In Unconventional Resources Technology Conference, No. 2170906: 15 p. San Antonio. doi: 10.15530/urtec-2015-2170906.

Macquaker, J.H. 1994. A lithofacies study of the Peterborough Member, Oxford Clay Formation (Jurassic), UK: an example of sediment bypass in a mudstone succession. Journal of the Geological Society 151 (1): 161-172. doi: 10.1144/gsjgs.151.1.0161.

Macquaker, J.H.; Gawthorpe, R.L. 1993. Mudstone lithofacies in the Kimmeridge Clay Formation, Wessex Basin, southern England: implications for the origin and controls of the distribution of mudstones. Journal of Sedimentary Research 63 (6): 1129-1143.

Miall, A.D. 1985. Architectural-element analysis: a new method of facies analysis applied to fluvial deposits. Earth-Science Reviews 22 (4): 261-308.

Mignard, S.L.; Mulder, T.; Martínez, P.; Charlier, K.; Rossignol, L.; Garlan, T. 2017. Deep-sea terrigenous organic carbon transfer and accumulation: Impact of sea-level variations and sedimentation processes off the Ogooue River (Gabon). Marine and Petroleum Geology 85: 35-53.

Mitchum, R.M.; Uliana, M.A. 1985. Seismic stratigraphy of carbonate depositional sequences, Upper Jurassic-Lower Cretaceous, Neuquén Basin, Argentina. In Seismic Stratigraphy, II: an Integrated Approach to Hydrocarbon Exploration (Berg, O.; Woolverton, D.; editors). American Association of Petroleum Geologists, Memoir 39: 255-274.

Mosquera, A.; Silvestro, J.; Ramos, V.; Alarcón, M.; Zubiri, M. 2011. La estructura de la Dorsal de Huincul. In Congreso Geológico Argentino, No. 8, Actas: 385 397. San Luis.

Mpodozis, C.; Ramos, V. 1989. The Andes of Chile and Argentina. In Geology of the Andes and its relation to hydrocarbon and mineral resources: Circum-Pacific
Council for Energy and Mineral Resources (Ericksen, G.E.; Cañas Pinochet, M.T.; Reinemud, J.A.; editors). Earth Sciences Series 11: 59-90. Houston.

Mulder, T.; Chapron, E. 2011. Flood deposits in continental and marine environments: character and significance. In Sediment transfer from shelf to deep water-Revisiting the delivery system (Slatt, R.M.; Zavala, C.; editors). American Association of Petroleum Geologists, Studies in Geology 61: 1-30. Tulsa.

Mulder, T.; Syvitski, J.P.; Migeon, S.; Faugeres, J.C.; Savoye, B. 2003. Marine hyperpycnal flows: initiation, behavior and related deposits. A review. Marine and Petroleum Geology 20 (6): 861-882.

Mutti, E. 1992. Turbidite sandstones. Azienda Generale Italiana Petroli (AGIP), Istituto di Geologia, Università di Parma: 275 p. San Donato Milanese.

Mutti, E.; Gulisano, C.A.; Legarreta, L. 1994. Anomalous systems tracts stacking patterns within third order depositional sequences (Jurassic-Cretaceous Back Arc Neuquén Basin, Argentine Andes). In Second High-Resolution Sequence Stratigraphy Conference, Abstracts: 137-143. Tremp.

Mutti, E.; Davoli, G.; Tinterri, R.; Zavala, C. 1996. The importance of ancient fluvio-deltaic systems dominated by catastrophic flooding in tectonically active basins. Memorie di Scienze Geologiche (Unpublished), Universita di Padova 48 (1): 233-291. Italia.

Naipauer, M.; Lescano, M.; Zavala, C.; AguirreUrreta, B.; Pimentel, M.; Ramos, V. 2015. Estudio multidisciplinario en la Formación Vaca Muerta: ambiente de sedimentación, bioestratigrafía, edades $\mathrm{U}-\mathrm{Pb}$ en circones y áreas de proveniencia del Miembro Huncal. In Congreso Geológico Chileno, No. 14, Resúmenes Expandidos Electrónicos. La Serena.

Nakajima, T. 2006. Hyperpycnites deposited $700 \mathrm{~km}$ away from river mouths in the Central Japan Sea. Journal of Sedimentary Research 76 (1): 59-72.

O'Brien, N.R.; Slatt, R.M. 1990. Argillaceous rock atlas. Springer-Verlag: 141 p. New York. doi: 10.1007/9781-4612-3422-7.

Otharán, G.A.; Zavala, C. 2016. Reconocimiento de turbiditas fangosas en la Formación Vaca Muerta (Jurásico tardío-Cretácico temprano), Neuquén, Argentina. In Simposio Argentino del Jurásico, No. 6, Actas: p. 30. Malargüe.

Otharán, G.A.; Zavala, C.; Arcuri, M. 2017. Reevaluación de los procesos de acumulación de lutitas bituminosas a partir del estudio de intervalos cementados. Formación Vaca Muerta (Tithoniano temprano-Valanginiano temprano), Cuenca Neuquina. In Congreso 
Geológico Argentino, No. 20, Actas Simposio Geología de la Formación Vaca Muerta: 97-102. Tucumán.

Otharán, G.A.; Zavala, C.; Arcuri, M.; Marchal, D.; Köhler, G.; Di Meglio, M.; Zorzano, A. 2018a. The role of fluid mud flows in the accumulation of organic-rich shales. The Upper Jurassic-Lower Cretaceous Vaca Muerta Formation, Neuquén Basin, Argentina. In Congreso de Exploración y Desarrollo de Hidrocarburos, No. 10, Actas Simposio de Recursos no Convencionales: 61-90. Mendoza.

Otharán, G.A.; Zavala, C.; Arcuri, M.; Di Meglio, M.; Zorzano, A.; Marchal, D.; Köhler, G. 2018b. Fangolitas bituminosas asociadas a flujos fluidos de fango, Formación Vaca Muerta (TithonianoValanginiano), Cuenca Neuquina, Argentina. In Reunión Argentina de Sedimentología, No. 16, Actas: p. 175. General Roca.

Plint, A.G.; Macquaker, J.H.; Varban, B.L. 2012. Bedload transport of mud across a wide, storm-influenced ramp: Cenomanian-Turonian Kaskapau Formation, western Canada foreland basin. Journal of Sedimentary Research 82 (11): 801-822.

Potter, P.E.; Maynard, J.B.; Pryor, W.A. 1980. Sedimentology of Shale. Springer Verlag: 303 p. Nueva York.

Potter, P.E.; Maynard, J.B.; Depetris, P.J. 2005. Mud and mudstones: Introduction and overview. Springer Science y Business Media: 304 p. Alemania.

Pose, F.; Gangui, A.; Galeazzi, S. 2014. Estratigrafía secuencial del intervalo Quintuco-Vaca Muerta en el Engolfamiento Neuquino, Cuenca Neuquina, Argentina. In Congreso de Exploración y Desarrollo de Hidrocarburos, No. 9, Simposio de Recursos no Convencionales: ampliando el horizonte energético: 341-364. Mendoza.

Reijenstein, H.; Lanusse, I.; Oviedo, P.; Licitra, D.; Sotelo, D.; Vittore, F.; Quiroga, J.; González Tomassini, F. 2017. ¿Deslizamientos en Vaca Muerta? Observaciones e integración de datos sísmicos, pozos y coronas en el yacimiento Loma Campana, Cuenca Neuquina, Argentina. In Congreso Geológico Argentino, No. 20, Simposio Geología de la Formación Vaca Muerta: 122-129. Tucumán.

Reineck, H.E.; Singh, I.B. 1971. Der Golf von Gaeta (Tyrrhenisches Meer); III, Die Gefuege von Vorstrandund Schelfsedimenten. Senckenbergiana Marítima 3: 185-194.

Sanders, J.E. 1965. Primary sedimentary structures formed by turbidity currents and related sedimentation mechanisms. In Primary sedimentary structures and their hydrodinamic interpretation (Middleton, G.V.; editor). Society of Economic Paleontologists and Mineralogists, Special Publications 12: 192-219.

Sattler, F.; Domínguez, R.F.; Fantín, M.; Desjardins, P.; Reijenstein, H.; Benoit, S.; Borgnia, M.; Vittore, F.; González Tomassini, F.; Feinstein, E.; Kietzmann, D.; Marchal, D. 2016. Anexo 1. In Transecta Regional de la Formación Vaca Muerta (González, G.; Vallejo, D.; Desjardins, P.; González Tomassini, F.; Kietzmann, D.; Rivarola, L.; Domínguez, F.; editores). Instituto Argentino del Petróleo y Gas (IAPG): p. 245.

Scasso, R.A.; Alonso, M.S.; Lanés, S.; Villar, H.J.; Lippai, H. 2002. Petrología y geoquímica de una ritmita margacaliza del Hemisferio Austral: el Miembro Los Catutos (Formación Vaca Muerta), Tithoniano medio de la Cuenca Neuquina. Revista de la Asociación Geológica Argentina 57 (2): 143-159.

Scasso, R.A.; Alonso, M.S.; Lanés, S.; Villar, H.J.; Laffitte, G. 2005. Geochemistry and petrology of a Middle Tithonian limestone-marl rhythmite in the Neuquén Basin, Argentina: depositional and burial history. Geological Society of London, Special Publications 252 (1): 207-229.

Schieber, J. 1994. Reflection of deep versus shallow water deposition by small scale sedimentary features and microfabrics of the Chattanooga Shale in Tennessee. Canadian Society of Petroleum Geologists, Memoir 17: 773-784.

Schieber, J. 1998. Sedimentary features indicating erosion, condensation, and hiatuses in the Chattanooga Shale of central Tennessee; relevance for sedimentary and stratigraphic evolution. In Mudstones and Shales, vol. 1, Characteristics at the Basin Studies, Sedimentology and Paleontology (Schieber, J.; Zimmerle, W.; Sethi, P.; editors). Schweizerbart'sche Verlagsbuchhandlung: 187-215. Stuttgart.

Schieber, J. 2011. Reverse Engineering Mother Nature-Shale Sedimentology from an Experimental Perspective. Sedimentary Geology 238 (1): 1-22.

Schieber, J. 2016. Mud-redistribution in epicontinental basins-Exploring likely processes. Marine and Petroleum Geology 71: 119-133.

Schieber, J.; Southard, J.B. 2009. Bedload transport of mud by floccule ripples: direct observation of ripple migration processes and their implications. Geology 37 (6): 483-486.

Schieber, J.; Yawar, Z. 2009. A new twist on mud deposition: mud ripples in experiment and rock record. The Sedimentary Record 7 (2): 4-8. 
Schieber, J.; Southard, J.B.; Thaisen, K.G. 2007. Accretion of mudstone beds from migrating floccule ripples. Sciences 318 (5857): 1760-1763.

Schieber, J.; Southard, J.B.; Schimmelmann, A. 2010. Lenticular shale fabrics resulting from intermittent erosion of water-rich muds: interpreting the rock record in the light of recent flume experiments. Journal of Sedimentary Research 80 (1): 119-128.

Schieber, J.; Southard, J.B.; Kissling, P.; Rossman, B.; Ginsburg, R. 2013. Experimental deposition of carbonate mud from moving suspensions: importance of flocculation and implications for modern and ancient carbonate mud deposition. Journal of Sedimentary Research 83 (11): 1025-1031.

Schlanger, S.O.; Arthur, M.A.; Jenkyns, H.C.; Scholle, P.A. 1987. The Cenomanian-Turonian Oceanic Anoxic Event, I. Stratigraphy and distribution of organic carbon-rich beds and the marine $\delta^{13} \mathrm{C}$ excursion. The Geological Society, Special Publications 26 (1): 371-399. Londres.

Seilacher, A.; Einsele, G. 1982. Cyclic and event stratification. Springer-Verlag: 531 p. Berlín.

Sellés-Martínez, J. 1996. Concretion morphology, classification and genesis. Earth-Science Reviews 41 (3): 177-210.

Sorby, H.C. 1908. On the application of quantitative methods to the study of the structure and history of rocks. Quarterly Journal of the Geological Society 64 (1-4): 171-233.

Soyinka, O.A.; Slatt, R.M. 2008. Identification and micro-stratigraphy of hyperpycnites and turbidites in Cretaceous Lewis Shale, Wyoming. Sedimentology 55 (5): 1117-1133.

Spalletti, L.A.; Veiga, G.D.; Schwarz, E.; Franzese, J. 2008. Depósitos de flujos gravitacionales subácueos de sedimentos en el flanco activo de la Cuenca Neuquina durante el Cretácico Temprano. Revista de la Asociación Geológica Argentina 63 (3): 442-453.

Stetten, E.; Baudin, F.; Reyss, J.L.; Martínez, P.; Charlier, K.; Schnyder, J.; Rabouille, C.; Dennielou, B.; Coston-Guarini, J.; Pruski, A. 2015. Organic matter charac-terization and distribution in sediments of the terminal lobes of the Congo deep-sea fan: evidence for the direct influence of the Congo River. Marine Geology 369: 182-195.

Stinco, L.P.; Barredo, S.P. 2014. Vaca Muerta Formation: An example of shale heterogeneities acontrolling hydrocarbon accumulations. In Unconventional Resources Technology Conference, No. 1922563. American Association of Petroleum Geologists: 15 p. Denver. doi: 10.15530/urtec-2014-1922563.
Stipanicic, P.N.; Rodrigo, F.; Baulíes O.L.; Martínez, C.G. 1968. Las formaciones presenonianas del denominado Macizo Nordpatagónico y regiones adyacentes. Revista de la Asociación Geológica Argentina 23 (2): 367-388.

Stow, D.A.; Shanmugam, G. 1980. Sequence of structures in fine-grained turbidites: comparison of recent deep-sea and ancient flysch sediments. Sedimentary Geology 25 (1-2): 23-42.

Stow, D.A.; Piper, D.J. 1984. Deep-water fine-grained sediments: facies models. Geological Society, Special Publications 15 (1): 611-646. Londres.

Stow, D.A.; Mayall, M. 2000. Deep-water sedimentary systems: new models for the $21^{\text {st }}$ century. Marine and Petroleum Geology 17 (2): 125-135.

Stow, D.A.; Huc, A.Y.; Bertrand, P. 2001. Depositional processes of black shales in deep water. Marine and Petroleum Geology 18: 491-498.

Tyson, R.V.; Wilson, R.C.; Downie, C. 1979. A stratified water column environmental model for the type Kimmeridge Clay. Nature 277 (5695): 377-380.

Vail, P.R.; Audemard, F.; Bowman, S.A.; Eisner, P.N.; PérezCruz, C. 1992. The stratigraphic signatures of tectonics, eustasy and sedimentology-an overview. In Cycles and events in stratigraphy (Einsele, G.; Ricken, W.; Seilacher, A.; editors). Springer Verlag: 617-659. Berlín.

Vergani, G.D.; Tankard, A.J.; Belotti, H.J.; Welsink, H.J. 1995. Tectonic evolution and paleogeography of the Neuquén basin, Argentina. In Petroleum Basins of South America (Tankard, A.J.; Suárez, S.R.; Welsink, H.J.; editors). American Association of Petroleum Geologists, Memoir 62: 383-402.

Weaver, C. 1931. Paleontology of the Jurassic and Cretaceous from west central Argentina. University of Washington, Memoir 1: 594 p. Seattle.

Westphal, H.; Head, M.J.; Munnecke, A. 2000. Differential diagenesis of rhythmic limestone alternations supported by palynological evidence. Journal of Sedimentary Research 70 (3): 715-725.

Wilson, R.; Schieber, J. 2014. Muddy prodeltaic hyperpycnites in the Lower Genesee Group of Central New York, USA: Implications for mud transport in epicontinental seas. Journal of Sedimentary Research 84 (10): 866-874.

Wilson, R.; Schieber, J. 2015. Sedimentary Facies and Depositional Environment of the Middle Devonian Geneseo Formation of New York, USA. Journal of Sedimentary Research 85 (11): 1393-1415.

Zavala, C.; Arcuri, M. 2016. Intrabasinal and extrabasinal turbidites: Origin and distinctive characteristics. Sedimentary Geology 337: 36-54. 
Zavala, C.; Ponce, J.J.; Arcuri, M.; Drittanti, D.; Freije, H.; Asensio, M. 2006. Ancient lacustrine hyperpycnites: a depositional model from a case study in the Rayoso Formation (Cretaceous) of westcentral Argentina. Journal of Sedimentary Research 76 (1): 41-59.

Zavala, C.; Arcuri, M.; Gamero, H.; Contreras, C.; Di Meglio, M. 2011. A genetic facies tract for the analysis of sustained hyperpycnal flow deposits.
In Sediment Transfer from Shelf to Deep WaterRevisiting the Delivery System (Slatt, R.M.; Zavala, C.; editors). American Association of Petroleum Geologists, Studies in Geology 61: 31-51.

Zhang, X.; Dalrymple, R.W.; Lin, C.M. 2017. Facies and stratigraphic architecture of the late pleistocene to early holocene tide-dominated paleo-changjiang (yangtze river) delta. Geological Society of America Bulletin 130 (3-4): 455-483.

Manuscrito recibido: Septiembre 08, 2017; revisado/aceptado: Marzo 29, 2019; disponible en línea: Enero 31, 2020. 